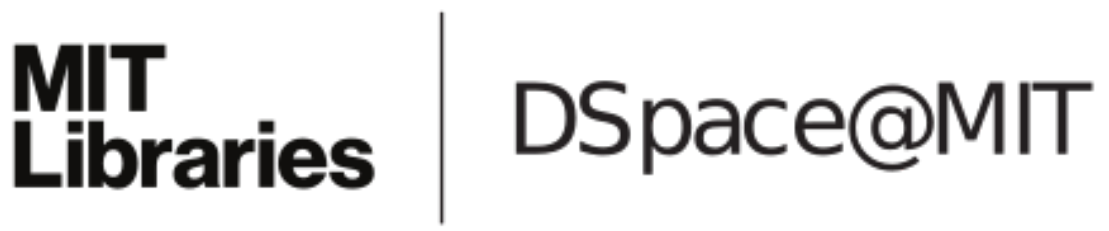

\author{
MIT Open Access Articles
}

A Review of Electrospun Carbon Fibers as
Electrode Materials for Energy Storage

The MIT Faculty has made this article openly available. Please share how this access benefits you. Your story matters.

Citation: Mao, Xianwen, T. Hatton, and Gregory Rutledge. "A Review of Electrospun Carbon Fibers as Electrode Materials for Energy Storage." COC 17, no. 13 (June 1, 2013): 1390-1401.

As Published: http://dx.doi.org/10.2174/1385272811317130006

Publisher: Bentham Science

Persistent URL: http://hdl.handle.net/1721.1/92409

Version: Author's final manuscript: final author's manuscript post peer review, without publisher's formatting or copy editing

Terms of use: Creative Commons Attribution-Noncommercial-Share Alike 


\title{
A Review of Electrospun Carbon Fibers as Electrode Materials for Energy Storage
}

Xianwen Mao, T. Alan Hatton, and Gregory C. Rutledge*

Department of Chemical Engineering, Massachusetts Institute of Technology

77 Massachusetts Avenue, Cambridge

Massachusetts, 02139, USA

E-mail: rutledge@mit.edu

\begin{abstract}
:
The applications of electrospun carbon fiber webs to the development of energy storages devices, including both supercapacitors and lithium ion batteries (LIB), are reviewed. Following a brief discussion of the fabrication process and characterization methods for ultrafine electrospun carbon fibers, recent advances in their performance as supercapacitors and LIBs anode materials are summarized. Optimization of the overall electrochemical properties of these materials through choice of thermal treatment conditions, incorporation of additional active components (such as carbon nanotubes, metal oxides, and catalysts), and generation of novel fibrous structures (such as core-shell, multi-channel or porous fibers) is highlighted. Further challenges related to improving the conductivity, surface area, and mechanical properties of the carbon nanofiber webs, as well as the scale-up ability of the fabrication technique, are discussed.
\end{abstract}

Keywords: electrospinning, carbon nanofiber, energy storage, supercapacitor, lithiumion battery 


\section{Introduction}

The development of energy storage devices is gaining extensive research interest due to growing world population, global climate change, concerns about exhaustion of fossil fuels, and the urgent need to meet the challenges for efficient storage of energy generated by some of the newer but intermittent sources such as solar and wind power. Supercapacitors $^{1-3}$ and lithium ion batteries (LIB) ${ }^{4-7}$ represent the frontier of this research effort, and they have become increasingly important in our daily lives, powering numerous portable consumer electronic devices (e.g., cell phones, laptops, PDAs), hybrid electric vehicles, and even other heavy-duty industrial scale systems. The development of new materials that can provide efficient means for energy conversion and storage, as well as the advancement of our understanding of the electrochemical interfaces at the microor nanoscale, plays an essential role in the design of future generations of supercapacitor and LIB devices.

Supercapacitors (i.e., electrochemical capacitors) constitute a class of capacitors that contain an electrolyte solution in place of a dielectric layer. Recently there has been growing interest in the development of robust supercapacitor devices for energy storage and harvesting mainly because of their high capacitance, long cycle life, and superior power and energy density. ${ }^{7-15}$ Depending upon the charge storage mechanism and the active materials used, supercapacitors are generally categorized as either electrochemical double layer capacitors (EDLC) or pseudocapacitors. ${ }^{7}$ EDLCs store electrical energy using reversible physical adsorption of ions, without any chemical reactions, from an electrolyte solution onto two porous electrodes to form an electric double layer at an electrode-electrolyte interface (Figure 1). Supercapacitor devices can be composed using 
the same material for the cathode and anode, in a symmetric device, or using different materials for each electrode, in an asymmetric device. Pseudocapacitors are fundamentally different from EDLCs in the way in which charge is stored, since they do not rely on the traditional charge separation mechanism that is typical of an electrostatic capacitor, but rather on a fast surface or near-surface Faradaic charge-transfer mechanism which gives them their "pseudo"-capacitive behavior. Highly porous carbon materials with high conductivity and electrochemical stability, such as activated, template and carbide-derived carbon, carbon fibers, fabrics, nanotubes, "onions", nanocages, nano"horns", and graphene-based nanomaterials, have been researched extensively for EDLCs. ${ }^{7,8,13-17}$ Well-known examples of pseudocapacitive materials include metal oxides $^{18,19}$ and conducting polymers, ${ }^{7}$ which can rely on fast and reversible redox reactions that occur on the electrode surface to store energy.

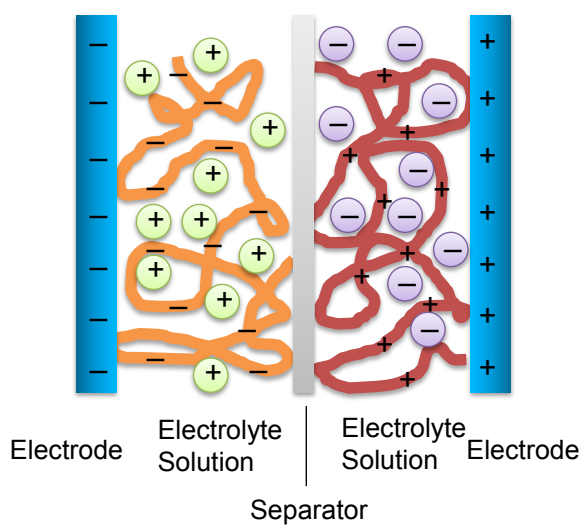

Figure 1. Schematic of an electrochemical double layer capacitor (EDLC). The thick orange and red lines represent conductive porous materials. The circles with the plus and minus signs represent the cations and anions in the electrolyte solution, respectively. 
Lithium ion batteries were introduced in 1990 by Sony, following pioneering work by Whittingham, Scrosati and Armand. ${ }^{20}$ LIBs have found significant applications in powering a great variety of electronic devices, and have recently been exploited in large scale applications such as in various types of electrical vehicles and in energy storage devices for utility grids. A typical commercial lithium-ion battery is composed of a graphite negative electrode (anode), a non-aqueous liquid electrolyte, and a positive electrode (cathode) formed from layered $\mathrm{LiCoO}_{2}$ (Figure 2). Upon charging, lithium ions are extracted from the layered $\mathrm{LiCoO}_{2}$ intercalation host, pass through the electrolyte solution, and intercalate between the graphite layers in the anode. Discharging is the reverse process, where the electrons transport through the external circuit. Extensively studied LIB anode materials include carbon, ${ }^{21}$ silicon, ${ }^{22-24}$ and tin, ${ }^{25}$ among others, while the typical examples of cathode materials include $\mathrm{LiMn}_{2} \mathrm{O}_{4},{ }^{26,27} \mathrm{LiFePO}_{4},{ }^{28-30}$ and $\mathrm{V}_{2} \mathrm{O}_{5}{ }^{31}$ These research efforts aim to meet the increasingly challenging standards for the future applications of LIBs, such as improved energy density, power density, and cycle life. 


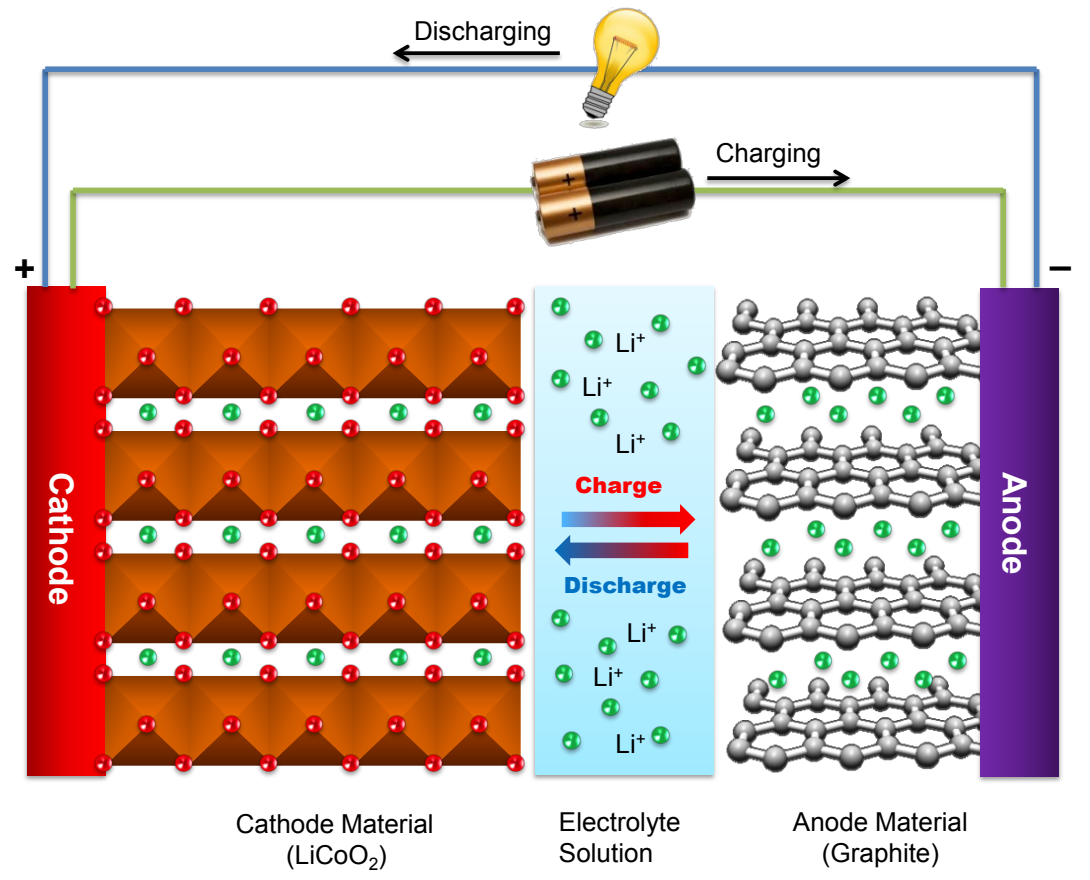

Figure 2. A typical configuration of a commercially available lithium ion battery illustrating the charging/discharging intercalation mechanism.

Electrospinning of an appropriate precursor solution to produce polymer fibers with submicron diameter, followed by thermal treatment to remove heteroatoms (i.e. to carbonize the polymer fibers), is a simple and low-cost approach to generate selfsupported webs composed of continuous ultrafine carbon fibers. ${ }^{32}$ The free-standing nature of the electrospun carbon fiber webs offers unique advantages for energy devices since it eliminates the need for using binders or substrates, thereby increasing the mass fraction of the active materials in a supercapacitor cell and improving the energy density. Moreover, processing conditions such as electrospinning parameters, composition of the precursor solution, and thermal treatment procedures can be used to control flexibly the morphology (e.g. fiber diameter, surface area, and porosity) as well as the electrical conductivity of the electrospun carbon fiber webs, which are two essential factors that 
have significant effects on their electrochemical energy storage capabilities and rate performance.

In this review, following a brief discussion of the fabrication method for electrospun carbon fibers (i.e., electrospinning and thermal treatment) and their methods of characterization, we concentrate on the applications of electrospun carbon nanofiber webs to the development of energy storages devices, including both supercapacitors and lithium ion batteries.

\section{Carbon Nanofibers Fabricated via Electrospinning and Thermal Treatment}

\subsection{Electrospinning of Polymer Solutions.}

Electrospinning of polymer solutions gives rise to the generation of ultrafine fibers with diameters controlled to be in the micrometer to nanometer range. As shown in Figure 3, a conventional electrospinning set-up involves three major components: a high voltage power supply, a spinneret (e.g., a syringe or pipette tip), and a grounded collector (typically a flat metal plate or a rotating drum). ${ }^{33}$ Briefly, the electrospinning technique is based on the application of an electric field to a drop of polymer solution on the tip of a spinneret. As the intensity of the electric field increases, the surface of this drop elongates to form a conical shape known as the Taylor cone (see Figure 4 (h)). When the applied electric field reaches a critical value, the repulsive electrical forces overcome the surface tension of the drop, and a charged jet of the solution is ejected from the tip of the cone and accelerates downfield. An electrohydrodynamic whipping instability of the jet occurs between the tip and the collector, which leads to further stretching of the liquid filament and the evaporation of the solvent to generate solidified continuous, micro- or 
nanofibers on the grounded collector. Alternatively, jets can be generated from free liquid surfaces such as films, drops or bubbles, without the need for a spinneret; the subsequent acceleration, whipping and solidification to form fibers is similar to those in the conventional technique. ${ }^{34}$ The often-cited advantages of electrospinning include ease of operation, efficiency, low cost, high yield, and high degree of reproducibility of the obtained materials. The versatility of electrospinning is reflected in the nature of electrospinnable materials as well as the different forms of fiber assemblies and architectures.

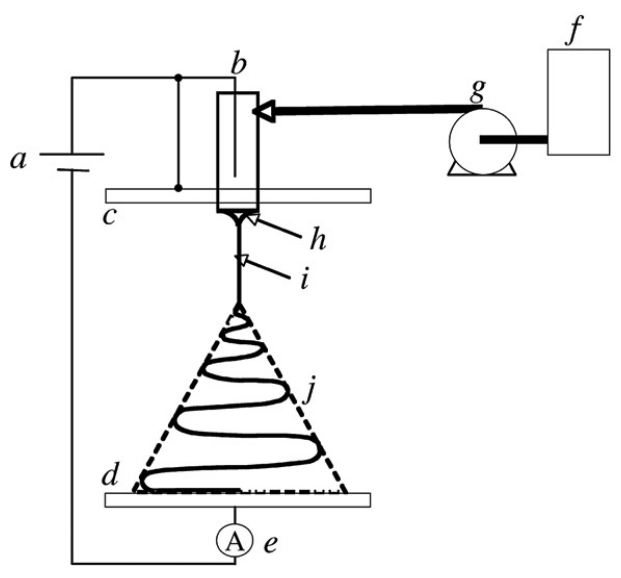

Figure 3. Schematic of the conventional electrospinning process. (a) high voltage power supply; (b) charging device; (c) high potential electrode (e.g. flat plate); (d) collector electrode (e.g. flat plate); (e) current measurement device; (f) fluid reservoir; (g) flow rate control; (h) cone; (i) thinning jet; (j) instability region. Reprinted with permission from reference 33. Copyright 2007 Elsevier.

2.2 Thermal Treatment of Polymer Fibers to Form Carbonaceous Fibers.

If a polymer with a high carbon yield (e.g., polyacrylonitrile (PAN) in most cases) is used to produce nanofibers from electrospinning, subsequent high temperature thermal 
treatment can convert the polymer fibers to carbonaceous fibers. The formation of carbon fibers from precusor polymer fibers generally includes stabilization, carbonization, and sometimes activation (to modify morphology and surface chemistry) if high ion adsorption capacity or improved electrochemical properties are desired. Stabilization is necessary to prevent precursor fibers from fusing together during carbonization since this step converts thermoplastic precursor fibers to highly condensed thermosetting fibers by complicated chemical and physical reactions (e.g., dehydrogenation, cyclization and polymerization). It should be noted that the heating rate during stabilization is usually maintained at a relatively low value (e.g., $3{ }^{\circ} \mathrm{C} / \mathrm{min}$ ) to avoid the release of a large amount of heat that might cause loss of fiber orientation and melting of polymers. Carbonization is often carried out in an inert gas atmosphere (e.g. nitrogen or argon), which prevents oxidation, removes heteroatoms, and generates the pyrolysis products such as $\mathrm{N}_{2}, \mathrm{CO}_{2}, \mathrm{H}_{2} \mathrm{O}$, etc. This process is often accompanied by a morphological change from smooth polymer fiber to wrinkled carbonaceous fibers with a decrease in fiber diameter and an increase in surface area.

\subsection{Characterization Methods of Electrospun Carbon Nanofibers}

The morphology of electrospun carbon fibers, such as fiber diameter and surface topology, is usually characterized by scanning electron microscopy (SEM) and transmission electron microscopy (TEM). The specific surface area and average pore size can be estimated from nitrogen adsorption isotherms, based on the Brunauer-EmmettTeller (BET) method.${ }^{16,35}$ Mesopore and micropore size distributions can be measured using the Barrett-Joiner-Halenda $(\mathrm{BJH})^{16}$ and Horvath-Kawazoe (HK) approaches, ${ }^{35}$ respectively. The degree of carbonization and important microstructural information can 
be estimated from Raman spectroscopy, electron energy loss spectroscopy (EELS), X-ray photoelectron spectroscopy (XPS) and X-ray diffraction (XRD). Raman analysis provides the relative intensity of the $\mathrm{D}$ and $\mathrm{G}$ bands $\left(R_{\mathrm{I}}\right)$, an indicator of the relative proportion of disordered to graphitic carbon. ${ }^{36}$ EELS can be used to quantify the ratio between the $\pi$ orbitals and $\sigma$ orbitals, which is $1 / 3$ and $0 / 4$ for purely $\mathrm{sp}^{2}$ and $\mathrm{sp}^{3}$ bonded carbons, respectively. If a reference sample that contains purely $\mathrm{sp}^{2}$ carbon is available (such as a standard graphite), ${ }^{15}$ the $\pi / \sigma$ ratio can be converted to the $\mathrm{sp}^{2} / \mathrm{sp}^{3}$ ratio. ${ }^{15,37}$ XPS C $1 \mathrm{~s}$ spectra provide direct measurements of the $\mathrm{sp}^{2} / \mathrm{sp}^{3}$ ratio based on the deconvolution of the high-resolution $\mathrm{C} 1 \mathrm{~s}$ peak into the $\mathrm{sp}^{2}$-bonded and $\mathrm{sp}^{3}$-bonded components. ${ }^{38,39}$ The crystallite size $\left(L_{\mathrm{c}}\right)$ and interlayer spacing $\left(d_{002}\right)$ can be estimated from XRD using the Scherrer and Bragg equations, respectively. ${ }^{40}$ The electrical conductivity of electrospun CNF mats is usually measured using a four-probe or a two-probe method. The four-probe method works well for webs composed densely-packed fibers when the electrical contacts are good between the fibers and the probes. This method avoids the contact resistance and gives direct measurement of sheet resistance. However, the four-probe method may give inconsistent results if the electrospun webs are highly porous, leading to poor contacts between fibers and the probes. The two-probe method is suitable for highly porous samples since the electrical contacts between the webs and the probes are made through the use of a conductive foil (such as a copper tape). It should be noted that in the two-probe method a correction should be made for the contact resistance, which can be obtained by varying the distance between the two probes, plotting the resistance versus the probe spacing and extrapolating the best linear fit to zero probe spacing. ${ }^{41}$ The electronic structures (i.e., valence band structures or density of electronic states) can be 
investigated using ultraviolet photoelectron spectroscopy (UPS). It is noteworthy that information on the density of states for semi-metal carbonaceous materials can also be inferred from their electrical conductivity. ${ }^{42,43}$

\section{Electrospun carbon fibers for supercapacitor applications}

As mentioned earlier, various forms of porous carbons such as activated fibers, templated carbons, and carbon nanotubes have been investigated for supercapacitor applications. Electrospun carbon fibers webs, which can be fabricated with varying fiber diameter, porosity and surface chemistry, enjoy unique advantages for the improvement of capacitor performance. Kim et al. first reported the application of electrospun carbon fibers to the development of supercapacitor devices. ${ }^{44}$ Following this report, several other groups developed various modifications and new fabrication methods to improve the electrochemical properties of electrospun carbon fibers for supercapacitor applications; these studies are listed in Table 1 with a summary of (1) the composition of the precursor solution, (2) thermal treatment conditions, (3) fiber diameter, (4) surface area, and (5) electrocapacitive performance.

Table 1. Electrospun CNF-based supercapacitor electrode materials.

\begin{tabular}{|c|c|c|c|c|c|}
\hline $\begin{array}{l}\text { Precursor } \\
\text { solution }\end{array}$ & $\begin{array}{l}\text { Thermal treatment } \\
\text { conditions }\end{array}$ & $\begin{array}{l}\begin{array}{l}\text { Fiber } \\
\text { diameter } \\
(\mathrm{nm})\end{array} \\
\end{array}$ & $\begin{array}{l}\text { Surface } \\
\text { area }\left(\mathrm{m}^{2} / \mathrm{g}\right)\end{array}$ & Electrocapactive performance & Ref. \\
\hline $\begin{array}{l}10 \mathrm{wt} \% \text { PAN in } \\
\text { DMF }\end{array}$ & $\begin{array}{l}\text { Stabilized at } 280{ }^{\circ} \mathrm{C} \text {, } \\
\text { carbonized and activated at } \\
700-800^{\circ} \mathrm{C} \text { in } \mathrm{N}_{2} \text { and steam }\end{array}$ & $200-400$ & 1230 & $\begin{array}{l}173 \mathrm{~F} / \mathrm{g} \text { at } 10 \mathrm{~mA} / \mathrm{g} \text { in } 30 \mathrm{wt} \% \\
\mathrm{KOH}\end{array}$ & 44 \\
\hline $\begin{array}{l}20 \text { wt } \% \text { PBI in } \\
\text { DMAc }\end{array}$ & $\begin{array}{l}\text { Carbonized and activated at } \\
750-850^{\circ} \mathrm{C} \text { for } 0.5 \mathrm{~h} \text { and } \\
\text { activated in } \mathrm{N}_{2} \text { and steam }\end{array}$ & $100-500$ & 1220 & $\begin{array}{l}178 \mathrm{~F} / \mathrm{g} \text { at } 5 \mathrm{~mA} / \mathrm{g} \text { in } 30 \mathrm{wt} \% \\
\mathrm{KOH}\end{array}$ & 45,46 \\
\hline $\begin{array}{l}10 \mathrm{wt} \% \text { PAN in } \\
\text { DMF }\end{array}$ & $\begin{array}{l}\text { Stabilized at } 280^{\circ} \mathrm{C}, \\
\text { carbonized and activated at } \\
800^{\circ} \mathrm{C} \text { in } \mathrm{N}_{2} \text { and steam }\end{array}$ & $200-350$ & 1160 & $\begin{array}{l}134 \mathrm{~F} / \mathrm{g} \text { at } 1 \mathrm{~mA} / \mathrm{cm}^{2} \mathrm{In} 6 \mathrm{M} \\
\mathrm{KOH}\end{array}$ & 47 \\
\hline $\begin{array}{l}\text { PAA in THF } \\
\text { and } \mathrm{MeOH}\end{array}$ & $\begin{array}{l}\text { Imidized at } 350{ }^{\circ} \mathrm{C} \text {, } \\
\text { carbonized at } 1000^{\circ} \mathrm{C} \text {, and } \\
\text { activated at } 800 \text { in } \mathrm{N}_{2} \text { and }\end{array}$ & $2000-3000$ & $940-2100$ & $\begin{array}{l}175 \mathrm{~F} / \mathrm{g} \text { at } 1000 \mathrm{~mA} / \mathrm{g} \text { in } 30 \mathrm{wt} \% \\
\mathrm{KOH}\end{array}$ & 48 \\
\hline
\end{tabular}




\begin{tabular}{|c|c|c|c|c|c|}
\hline & steam & & & & \\
\hline $\begin{array}{l}20 \mathrm{wt} \% \mathrm{PBI} \text { in } \\
\text { DMAc }\end{array}$ & $\begin{array}{l}\text { Carbonized and activated at } \\
700-850{ }^{\circ} \mathrm{C} \text { for } 0.5 \mathrm{~h} \text { in } \mathrm{N}_{2} \\
\text { and steam }\end{array}$ & 230 & $500-1220$ & $\begin{array}{l}202 \mathrm{~F} / \mathrm{g} \text { in } 1 \mathrm{M} \mathrm{H}_{2} \mathrm{SO}_{4} \text { at } 1 \\
\mathrm{~mA} / \mathrm{cm}^{2}\end{array}$ & 49 \\
\hline $\begin{array}{l}\text { PAN and Ru- } \\
\text { acac in DMF }\end{array}$ & $\begin{array}{l}\text { Stabilized at } 280{ }^{\circ} \mathrm{C}, \\
\text { carbonized and activated at } \\
800{ }^{\circ} \mathrm{C} \text { in } \mathrm{N}_{2} \text { and steam }\end{array}$ & $200-900$ & $428-531$ & $\begin{array}{l}391 \mathrm{~F} / \mathrm{g} \text { with } 7.31 \mathrm{wt} \% \mathrm{Ru} \\
\text { content in } 6 \mathrm{M} \mathrm{KOH} \text { at } 1 \mathrm{~mA} / \mathrm{cm}^{2}\end{array}$ & 50 \\
\hline $\begin{array}{l}10 \mathrm{wt} \% \mathrm{PAN} \\
\text { and } \mathrm{ZnCl}_{2} \text { in } \\
\text { DMF }\end{array}$ & $\begin{array}{l}\text { Stabilized at } 280^{\circ} \mathrm{C} \\
\text { carbonized at } 800^{\circ} \mathrm{C}\end{array}$ & $200-350$ & $310-550$ & $140 \mathrm{~F} / \mathrm{g}$ in $\mathrm{KOH}$ & 51 \\
\hline $\begin{array}{l}10 \mathrm{wt} \% \text { PAN } \\
\text { and } 3 \text { wt\% } \\
\text { MWCNT in } \\
\text { DMF } \\
\end{array}$ & $\begin{array}{l}\text { Stabilized at } 280^{\circ} \mathrm{C}, \\
\text { carbonized and activated at } \\
800^{\circ} \mathrm{C} \text {, coated by PPy }\end{array}$ & 230 & 742 & $333 \mathrm{~F} / \mathrm{g}$ in $6 \mathrm{M} \mathrm{KOH}$ at $1 \mathrm{~mA} / \mathrm{cm}^{2}$ & 52 \\
\hline $\begin{array}{l}10 \mathrm{wt} \% \mathrm{PAN} \\
\text { and } 10 \mathrm{wt} \% \\
\mathrm{~V}_{2} \mathrm{O}_{5} \text { in } \mathrm{DMF}\end{array}$ & $\begin{array}{l}\text { Stabilized at } 250{ }^{\circ} \mathrm{C}, \\
\text { carbonized and activated with } \\
\mathrm{KOH} \text { at } 800^{\circ} \mathrm{C} \text {, }\end{array}$ & - & 2800 & $\begin{array}{l}128 \mathrm{~F} / \mathrm{g} \text { in } 1 \mathrm{M}\left(\mathrm{C}_{2} \mathrm{H}_{5}\right)_{4} \mathrm{NBF}_{4} / \mathrm{PC} \\
\text { at } 1 \mathrm{~A} / \mathrm{g}\end{array}$ & 35 \\
\hline $\begin{array}{l}\text { PAN and CA in } \\
\text { DMF }\end{array}$ & $\begin{array}{l}\text { Stabilized at } 280^{\circ} \mathrm{C}, \\
\text { carbonized and activated at } \\
800{ }^{\circ} \mathrm{C}\end{array}$ & $250-700$ & 1160 & $245 \mathrm{~F} / \mathrm{g}$ in $6 \mathrm{M} \mathrm{KOH}$ at $1 \mathrm{~mA} / \mathrm{cm}^{2}$ & 53 \\
\hline $\begin{array}{l}7.2 \mathrm{wt} \% \text { PAN } \\
\text { and } 0.8 \mathrm{wt} \% \\
\text { MWCNT in } \\
\text { DMF } \\
\end{array}$ & $\begin{array}{l}\text { Stabilized at } 240^{\circ} \mathrm{C} \text {, } \\
\text { carbonized at } 700^{\circ} \mathrm{C} \text {, and } \\
\text { activated with } \mathrm{H}_{2} \mathrm{O}_{2} \text { vapor at } \\
600^{\circ} \mathrm{C}\end{array}$ & $\sim 500$ & 810 & $\begin{array}{l}310 \mathrm{~F} / \mathrm{g} \text { in } 1 \mathrm{M} \mathrm{H}_{2} \mathrm{SO}_{4} \text { at } 100 \\
\mathrm{~mA} / \mathrm{g}\end{array}$ & 54 \\
\hline $\begin{array}{l}\text { PAN and } \\
\text { Ni(OAc) in DMF }\end{array}$ & $\begin{array}{l}\text { Stabilized at } 2800^{\circ} \mathrm{C}, \\
\text { carbonized at } 1000^{\circ} \mathrm{C}\end{array}$ & $150-210$ & - & $\begin{array}{l}164 \mathrm{~F} / \mathrm{g} \text { in } 6 \mathrm{M} \mathrm{KOH} \text { at } 2 \mathrm{mV} / \mathrm{s} \\
\text { and at } 250 \mathrm{~mA} / \mathrm{g}\end{array}$ & 55 \\
\hline $\begin{array}{l}\text { PAN and PVP in } \\
\text { DMF }\end{array}$ & $\begin{array}{l}\text { Stabilized and carbonized } \\
\text { from } 300-970^{\circ} \mathrm{C} \text {, activated } \\
\text { by } \mathrm{CO}_{2} \text { at } 8500^{\circ} \mathrm{C}\end{array}$ & - & 531 & $220 \mathrm{~F} / \mathrm{g}$ in $1 \mathrm{M} \mathrm{H}_{2} \mathrm{SO}_{4}$ & 56 \\
\hline $\begin{array}{l}\text { PAN and TEOS } \\
\text { in DMF }\end{array}$ & $\begin{array}{l}\text { Stabilized at } 280^{\circ} \mathrm{C}, \\
\text { carbonized at } 800-1000{ }^{\circ} \mathrm{C}\end{array}$ & 150 & $980-1200$ & $160 \mathrm{~F} / \mathrm{g}$ in $6 \mathrm{M} \mathrm{KOH}$ at $1 \mathrm{~mA} / \mathrm{cm}^{2}$ & 57 \\
\hline $\begin{array}{l}\text { PAN and } \mathrm{AgNO}_{3} \\
\text { in DMF }\end{array}$ & $\begin{array}{l}\text { Stabilized at } 280{ }^{\circ} \mathrm{C}, \\
\text { carbonized and activated at } \\
800{ }^{\circ} \mathrm{C} \text { in } \mathrm{N}_{2} \text { and steam }\end{array}$ & 350 & 1096 & $150 \mathrm{~F} / \mathrm{g}$ in $6 \mathrm{M} \mathrm{KOH}$ at $1 \mathrm{~mA} / \mathrm{cm}^{2}$ & 58 \\
\hline $\begin{array}{l}\text { PAN in DMF + } \\
\text { pitch in THF }\end{array}$ & $\begin{array}{l}\text { Stabilized and carbonized at } \\
1000^{\circ} \mathrm{C}\end{array}$ & 150 & 966 & $130 \mathrm{~F} / \mathrm{g}$ in $6 \mathrm{M} \mathrm{KOH}$ at $1 \mathrm{~mA} / \mathrm{cm}^{2}$ & 59 \\
\hline $\begin{array}{l}\text { PAN and Ag } \\
\text { nanoparticles in } \\
\text { DMF }\end{array}$ & $\begin{array}{l}\text { Stabilized at } 250{ }^{\circ} \mathrm{C} \text { and } \\
\text { carbonized at } 1000^{\circ} \mathrm{C} \text { in } \mathrm{N}_{2}\end{array}$ & $200-500$ & - & & 60 \\
\hline
\end{tabular}

Improvements in the electrochemical capacitance of electrospun carbon

nanofibers have been achieved generally by three types of strategies: (1) manipulation of

fiber morphology and degree of graphitization by control of heat treatment conditions, use of catalysts during carbonization and/or activation, selection and combination of different polymer precursors such as PAN, polybenzimidazol (PBI), poly(amic acid) (PAA), pitch, polyvinylpyrrolidone (PVP) and cellulose acetate (CA); (2) inclusion of pseudocapacitive contribution into the carbon nanofibers through incorporation of redoxactive components such as metal oxides and conducting polymers; and (3) improvement 
of electrical conductivity by encapsulation of highly conductive components such as carbon nanotubes and metallic nanoparticles.

The effects of steam activation temperature on the electrocapacitive performance of PAN-based electrospun carbon fiber webs are summarized in Figure 4, which shows the specific capacity as a function of discharge current density for carbon fiber webs activated at 700,750 and $800{ }^{\circ} \mathrm{C}$ in steam. ${ }^{44}$ The maximum specific capacitance obtained was $175 \mathrm{~F} / \mathrm{g}$ at $10 \mathrm{~mA} / \mathrm{g}$ for the carbon fiber web activated at $700{ }^{\circ} \mathrm{C}$ (Figure $4 \mathrm{a}$ ); however the capacitance dropped quickly to $75 \mathrm{~F} / \mathrm{g}$, with an increase in current density to $1000 \mathrm{~mA} / \mathrm{g}$. Interestingly, the carbon fiber webs synthesized at $800{ }^{\circ} \mathrm{C}$ exhibited the highest capacitance of $120 \mathrm{~F} / \mathrm{g}$ at the higher current density of $1000 \mathrm{~mA} / \mathrm{g}$ (Figure 4c). This was attributed to the high fraction of mesopore volume obtained at $800{ }^{\circ} \mathrm{C}$, since the ions solvated by water molecules in the mesopores would respond more quickly than those in the micropores at a higher current density. Zinc chloride, which acts as a catalyst for carbonization of PAN, was used to control fiber diameter and surface area of PANbased electrospun carbon fibers. ${ }^{51}$ As shown in Figure 5, with increasing zinc chloride content from 1 to 3 to $5 \mathrm{wt} \%$, the average diameters of the fibers decreased from 350 to 250 to $200 \mathrm{~nm}$, respectively. After carbonization, the sample with $5 \mathrm{wt} \%$ zinc chloride exhibited the highest capacitance, probably because it had the largest surface area, resulting from the catalytic activity of zinc chloride. Electrospinning of a solution of nickel acetate and PAN in DMF, followed by stabilization and carbonization, generated nickel-embedded carbon fibers. ${ }^{55}$ The specific capacitance of the carbon fiber electrode without the Ni loading was only $50 \mathrm{~F} / \mathrm{g}$, while the value for $22.4 \mathrm{wt} \% \mathrm{Ni} / \mathrm{carbon}$ electrode increased to $164 \mathrm{~F} / \mathrm{g}$. This increase was ascribed to the electrochemical catalysis effect of 
nickel. Microporous structures on the electrospun carbon fibers can also be created by incorporating tetraethoxy orthosilicate (TEOS) into PAN solution to improve the electrochemical capacitance. ${ }^{57}$ Using vanadium catalyst, pore size control in electrospun carbon fibers was achieved. ${ }^{35}$ In addition, electrospinning of bicomponent polymer solutions such as PAN $/ \mathrm{CA}^{53}$, PAN/PVP ${ }^{56}$, and PAN $/$ pitch $^{59}$ have been investigated to modulate the resulting carbon fiber structures and their capacitive behavior.

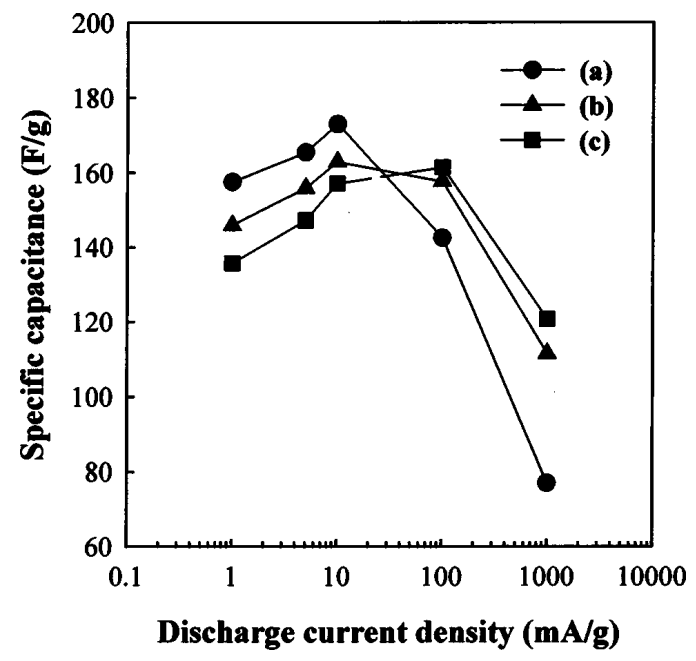

Figure 4. Specific capacitance as a function of discharge current density for PANbased electrospun carbon fiber webs treated at various activation temperatures in steam: (a) 700, (b) 750, and (c) $800^{\circ} \mathrm{C}$. Reprinted with permission from reference 44. Copyright 2003 American Institute of Physics. 


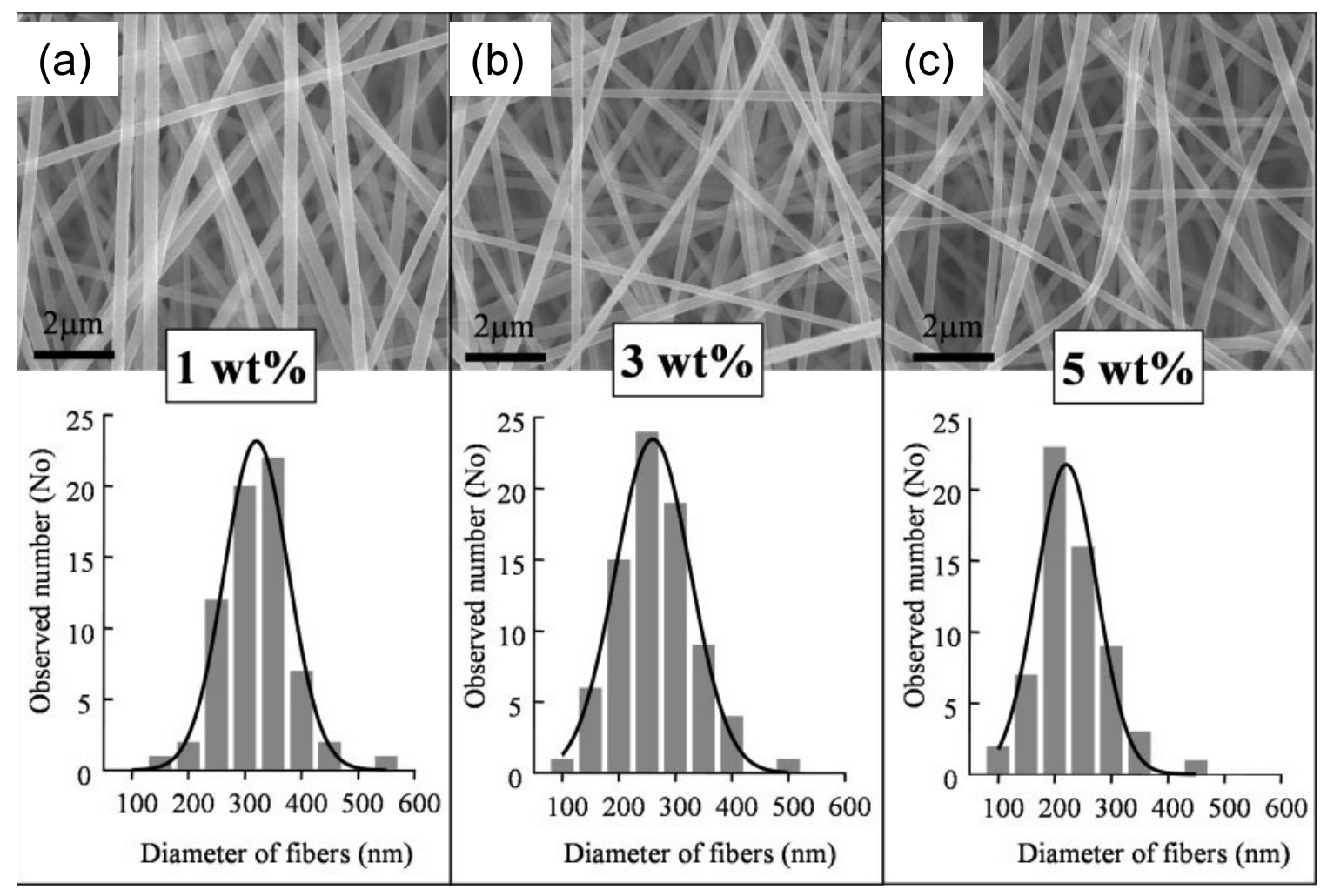

Figure 5. Field-emission scanning electron microscopy (FE-SEM) images of the electrospun organic fibers from PAN solutions containing different weight percents of zinc chloride, c) 1, d) 3, and e) $5 \mathrm{wt} \%$, and their corresponding diameter distributions. Reprinted with permission from reference 51. Copyright 2007 WILEY-VCH.

Incorporation of redox-active species into electrospun carbon fibers can improve significantly their electrochemical capacitance due to the simultaneous use of both charge storage mechanisms (i.e., electrical double layer and redox reactions). Rutheniumembedded carbon fibers were prepared by the processes of stabilization, carbonization, and activation after electrospinning a composite solution of ruthenium (III) acetylacetonate and PAN in DMF. ${ }^{50}$ The specific capacitances were enhanced greatly after incorporation of $\mathrm{Ru}$ nanoparticles into the carbon fibers. Figure 6 shows that the total capacitance (EDLC and pseudocapacitance combined) of the Ru-loaded carbon 
fibers increased with Ru content. The capacitance of electrospun carbon fibers without Ru was $140 \mathrm{~F} / \mathrm{g}$ whereas the value for the electrode with $7.31 \mathrm{wt} \% \mathrm{Ru}$ was increased to $391 \mathrm{~F} / \mathrm{g}$. This was attributed to the synergistic effects of enhanced electric double-layer capacitance as a result of the expansion of the average pore diameter as well as the added pseudocapacitance by the well-dispersed Ru nanoparticles.

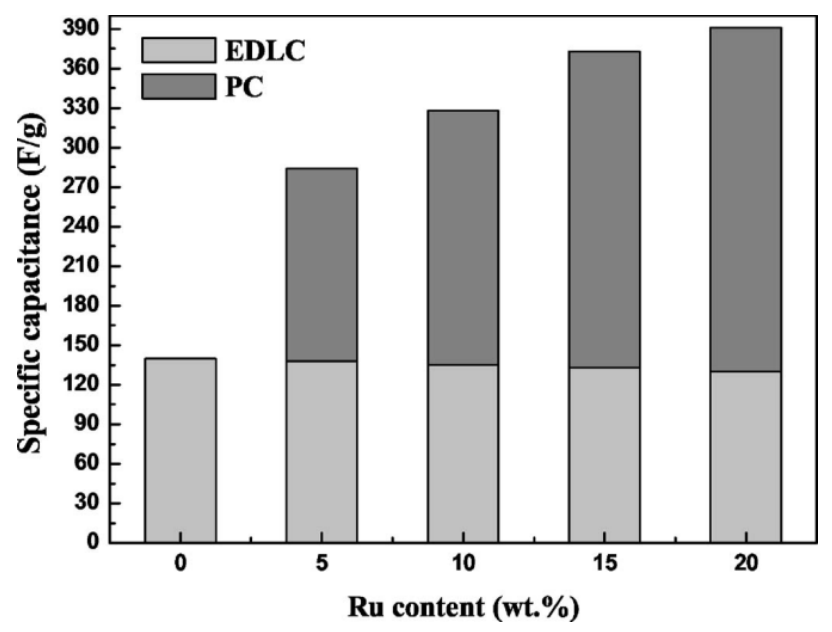

Figure 6. Specific capacitance of ruthenium-loaded electrospun carbon fiber electrodes at different $R$ u content. EDLC represents the contribution from the electrical double layer capacitance, while PC represents the contribution from the pseudocapacitance of Ru. Reprinted with permission from reference 50. Copyright 2007 The Electrochemical Society.

Improving the electrical conductivity of carbon fibers by loading highly conductive components is another approach to enhancing their electrochemical performance. Electrospinning is a unique method that can produce CNT-embedded fibers as a type of non-woven web. ${ }^{52,54}$ The electrochemical performance of the CNT-loaded fiber webs depends on how well the CNTs are distributed with the fiber webs. Three wt $\%$ MWCNT were dispersed in a $10 \mathrm{wt} \% \mathrm{PAN} / \mathrm{DMF}$ solution using a homogenizer, and the resultant 
CNT-embedded carbon fiber webs obtained after electrospinning and carbonization exhibited an increased EDLC capacitance of $180 \mathrm{~F} / \mathrm{g}$ in $6 \mathrm{M} \mathrm{KOH}^{52}$ This was explained by the observation that the addition of MWCNTs increased both the BET surface area and electrical conductivity of the electrospun carbon fibers. Moreover, coating of polypyrole (PPy) on the MWCNT-loaded fibers resulted in a further increase in capacitance due to the pseudocapacitive contribution from the electrochemically active polymer PPy. Silver nanoparticle-containing carbon fibers were prepared through electrospinning of a mixture of silver powders and PAN in DMF, followed by stabilization in air at $250{ }^{\circ} \mathrm{C}$ for $2 \mathrm{~h}$ and carbonization in $\mathrm{N}_{2}$ at $1000{ }^{\circ} \mathrm{C}$ for $2 \mathrm{~h}^{60} \mathrm{~A}$ tenfold decrease in resistance was observed when $1 \mathrm{wt} \%$ silver nanoparticles were incorporated into the carbon fibers, compared to the case without silver loading. Only slight improvement in conductivity was found when the silver concentration was further increased to $5 \mathrm{wt} \%$. For the $1 \mathrm{wt} \%$ silver concentration, the resistance was $4.5 \times 10^{-2}$ $\Omega \cdot \mathrm{cm}$, and for $3 \mathrm{wt} \%$ and $5 \mathrm{wt} \%$, it was $4.0 \times 10^{-2}$ and $3.5 \times 10^{-2} \Omega \cdot \mathrm{cm}$, respectively. However, when the silver content increased from 0 to 1 to 3 to $5 \mathrm{wt} \%$, the specific capacitance of the carbon fiber webs was enhanced significantly from 190 to 224 to 234 to $248 \mathrm{~F} / \mathrm{g}$.

\section{Electrospun carbon nanofibers as anode materials for lithium-ion batteries}

Rechargeable lithium-ion batteries now dominate the portable electronic market. Various types of carbonaceous materials including carbon particles, carbon nanotubes and carbon fibers have been investigated for LIB applications. Compared to natural graphite, which has a relatively low theoretical $\mathrm{Li}^{+}$storage capacity of $372 \mathrm{mAh} / \mathrm{g}$, PAN-

derived electrospun carbon fibers thermally treated at $1000{ }^{\circ} \mathrm{C}$ have been found to exhibit 
a slightly higher reversible discharge capacity of $450 \mathrm{mAh} / \mathrm{g} .{ }^{61}$ However, higher temperature treatment $\left(2800^{\circ} \mathrm{C}\right)$ led to a remarkable decrease in the LIB reversible capacity. To improve LIB performance, it is often necessary to incorporate into the carbon matrix another component that has a high $\mathrm{Li}^{+}$storage capacity such as silicon $(\mathrm{Si})$ or tin (Sn). Table 2 provides a summary of reports that describe electrospun carbon fiberbased materials for LIB anode applications, with emphasis on: (1) the composition of the precursor solution; (2) thermal treatment conditions; (3) functionalities/active components; and (4) optimal reversible capacity achieved in each case, often using different testing conditions or material compositions.

Table 2. Electrospun carbon fiber-based anode materials for lithium-ion batteries.

\begin{tabular}{|c|c|c|c|c|}
\hline $\begin{array}{l}\text { Precursor } \\
\text { solution }\end{array}$ & Thermal treatment conditions & Functionalities/active components & $\begin{array}{l}\text { Optimal } \\
\text { reversible } \\
\text { capacity }(\mathrm{mAh} / \mathrm{g})\end{array}$ & Ref. \\
\hline $\begin{array}{l}10 \mathrm{wt} \% \text { PAN in } \\
\text { DMF }\end{array}$ & $\begin{array}{l}\text { Stabilized at } 280{ }^{\circ} \mathrm{C} \text {, carbonized at } \\
700-2800 \mathrm{C} \text { in } \mathrm{N}_{2}\end{array}$ & $\begin{array}{l}\text { Non-graphtizable carbon formed at } \\
\text { different pyrolysis temperatures }\end{array}$ & 450 & 61 \\
\hline $\begin{array}{l}\text { PAN and } \\
\mathrm{Co}(\mathrm{OAc})_{2} \text { in DMF }\end{array}$ & $\begin{array}{l}\text { Stabilized at } 230^{\circ} \mathrm{C} \text {, carbonized at } \\
600{ }^{\circ} \mathrm{C}\end{array}$ & $40 \mathrm{wt} \%$ Co loaded & 750 & 62 \\
\hline $\begin{array}{l}\text { PAN and Fe-acac } \\
\text { in DMF }\end{array}$ & $\begin{array}{l}\text { Stabilized at } 240{ }^{\circ} \mathrm{C} \text {, carbonized at } \\
700{ }^{\circ} \mathrm{C}\end{array}$ & $\mathrm{Fe}_{3} \mathrm{O}_{4}$ loaded & 1007 & 63 \\
\hline $\begin{array}{l}\text { PAN and } \\
\operatorname{Mn}(\mathrm{OAc})_{2} \text { in } \\
\text { DMF }\end{array}$ & $\begin{array}{l}\text { Stabilized at } 240{ }^{\circ} \mathrm{C} \text {, carbonized at } \\
700{ }^{\circ} \mathrm{C}\end{array}$ & $\mathrm{MnO}$ and $\mathrm{Mn}_{3} \mathrm{O}_{4}$ loaded & 800 & 64 \\
\hline $\begin{array}{l}\text { PAN, poly-L- } \\
\text { lactic acid and Si } \\
\text { in DMF }\end{array}$ & $\begin{array}{l}\text { Stabilized at } 240{ }^{\circ} \mathrm{C} \text {, carbonized at } \\
700{ }^{\circ} \mathrm{C}\end{array}$ & Si nanoparticle loaded & 1100 & 65 \\
\hline $\begin{array}{c}\text { PAN in DMF and } \\
\text { TBT in mineral } \\
\text { oil }\end{array}$ & $\begin{array}{l}\text { Dissolved out mineral oil in } \mathrm{n}- \\
\text { octane, carbonized at } 1000{ }^{\circ} \mathrm{C}\end{array}$ & Sn@carbon nanoparticles & 737 & 66 \\
\hline $\begin{array}{l}\text { PAN, PMMA and } \\
\text { tin octoate in } \\
\text { DMF }\end{array}$ & $\begin{array}{l}\text { Stabilized at } 250{ }^{\circ} \mathrm{C} \text {, carbonized at } \\
1000{ }^{\circ} \mathrm{C}\end{array}$ & $\begin{array}{l}\text { Multi-channels by removal of } \\
\text { PMMA during carbonization, tin } \\
\text { nanoparticle loaded }\end{array}$ & 648 & 67 \\
\hline $\begin{array}{l}\text { PAN and } \mathrm{ZnCl}_{2} \\
\text { in DMF }\end{array}$ & $\begin{array}{l}\text { Stabilized at } 280{ }^{\circ} \mathrm{C} \text {, carbonized at } \\
700{ }^{\circ} \mathrm{C}, \mathrm{Zn} \text { washed out by } \mathrm{HCl}\end{array}$ & $\mathrm{ZnCl}_{2}$ mixed carbon fibers & 400 & 68 \\
\hline $\begin{array}{l}\text { PAN and Si in } \\
\text { DMF }\end{array}$ & $\begin{array}{l}\text { Stabilized at } 280{ }^{\circ} \mathrm{C} \text {, carbonized at } \\
700{ }^{\circ} \mathrm{C}\end{array}$ & Si filled carbon $(\mathrm{Si} / \mathrm{C})$ & 855 & 69 \\
\hline $\begin{array}{l}\text { PVA and } \mathrm{Si} \text { in } \\
\text { water and } \mathrm{Na} \\
\text { alkyl- } \\
\text { benzenesulfonate }\end{array}$ & Heat treated at $500{ }^{\circ} \mathrm{C}$ & Si nanoparticle loaded & 892 & 70 \\
\hline $\begin{array}{l}\text { PAN and Si in } \\
\text { DMF }\end{array}$ & $\begin{array}{l}\text { Stabilized at } 280^{\circ} \mathrm{C} \text {, carbonized at } \\
700{ }^{\circ} \mathrm{C}\end{array}$ & Si nanoparticle loaded & 1281 & 71 \\
\hline $\begin{array}{l}\text { PAN and fumed } \\
\mathrm{SiO}_{2} \text { in DMF } \\
\end{array}$ & $\begin{array}{l}\text { Stabilized at } 280{ }^{\circ} \mathrm{C} \text {, carbonized at } \\
1000^{\circ} \mathrm{C}, \mathrm{SiO}_{2} \text { washed out by } \mathrm{HF}\end{array}$ & $\begin{array}{l}\text { Porous carbon fibers created by } \\
\text { removal of } \mathrm{SiO}_{2}\end{array}$ & 593 & 72 \\
\hline $\begin{array}{l}\text { PAN and } \\
\mathrm{Ni}(\mathrm{OAc})_{2} \text { in } \mathrm{DMF}\end{array}$ & $\begin{array}{l}\text { Stabilized at } 280^{\circ} \mathrm{C} \text {, carbonized at } \\
600{ }^{\circ} \mathrm{C}\end{array}$ & $\begin{array}{l}\text { Ni nanoparticles dispersed in carbon } \\
\text { fibers }\end{array}$ & 795 & 73 \\
\hline $\begin{array}{l}\text { PAN and } \\
\operatorname{Mn}(\mathrm{OAc})_{2} \text { in }\end{array}$ & $\begin{array}{l}\text { Stabilized at } 280{ }^{\circ} \mathrm{C} \text {, carbonized at } \\
700{ }^{\circ} \mathrm{C}\end{array}$ & $\mathrm{MnO}_{\mathrm{x}}$ loaded & 785 & 74 \\
\hline
\end{tabular}




\begin{tabular}{|c|c|c|c|c|}
\hline DMF & & & & \\
\hline $\begin{array}{l}\text { PAN and poly-L- } \\
\text { lactic acid in } \\
\text { DMF }\end{array}$ & $\begin{array}{l}\text { Stabilized at } 280^{\circ} \mathrm{C} \text {, carbonized at } \\
800^{\circ} \mathrm{C}\end{array}$ & $\begin{array}{l}\text { Porous carbon fibers from } \\
\text { bicomponent precursor solution }\end{array}$ & 435 & 75 \\
\hline $\begin{array}{l}\text { PVA and } \mathrm{SnCl}_{2} \\
\text { in } \mathrm{H}_{2} \mathrm{O}\end{array}$ & carbonized at $500{ }^{\circ} \mathrm{C}$ & $\mathrm{Sn} / \mathrm{C}$ composite fibers & 382 & 76 \\
\hline $\begin{array}{l}\text { PVA and } \mathrm{SnCl}_{2} \\
\text { in } \mathrm{H}_{2} \mathrm{O}\end{array}$ & carbonized at $550^{\circ} \mathrm{C}$ & $\mathrm{Sn}$ and $\mathrm{SnO}_{\mathrm{x}}$ loaded & 510 & 77 \\
\hline $\begin{array}{l}\text { PAN and } \\
\mathrm{Cu}(\mathrm{OAc})_{2} \text { in } \\
\mathrm{DMF}\end{array}$ & $\begin{array}{l}\text { Stabilized at } 280^{\circ} \mathrm{C} \text {, carbonized at } \\
600^{\circ} \mathrm{C}\end{array}$ & FCC-Cu loaded & 617 & 78 \\
\hline $\begin{array}{l}\text { PAN and } \mathrm{Si} \text { in } \\
\text { DMF }\end{array}$ & carbonized at $800-1200^{\circ} \mathrm{C}$ & Si nanoparticles loaded & 500 & 79 \\
\hline $\begin{array}{l}\text { PAN and } \\
\mathrm{LiFePO}_{4} \text { in } \mathrm{DMF}\end{array}$ & $\begin{array}{l}\text { Stabilized at } 280^{\circ} \mathrm{C} \text {, carbonized at } \\
700^{\circ} \mathrm{C}\end{array}$ & $\mathrm{LiFePO}_{4} / \mathrm{C}$ composite fibers & 160 & 80 \\
\hline $\begin{array}{l}\text { PAN, PMMA and } \\
\text { Si in DMF }\end{array}$ & $\begin{array}{l}\text { Stabilized at } 280^{\circ} \mathrm{C} \text {, carbonized at } \\
1000{ }^{\circ} \mathrm{C}\end{array}$ & Si@C core-shell fibers & 1384 & 81 \\
\hline
\end{tabular}

Si has been considered an excellent candidate for next-generation LIB anode materials since it has the highest known theoretical capacity of $4200 \mathrm{mAh} / \mathrm{g}$, significantly greater than the values for graphite and metal oxides. ${ }^{23,82}$ However, Si can experience large volume changes due to severe pulverization upon lithium insertion and extraction, which leads to reduced capacity and cycling stability. ${ }^{83}$ Dispersion of Si nanoparticles in a carbon matrix, which acts as both a structural buffer and an electroactive material, proves an effective strategy to improve the LIB performance of Si. Electrospinning of PAN and $\mathrm{Si}$ in DMF, followed by thermal treatment, generated carbon fibers with $\mathrm{Si}$ nanoparticles distributed both inside and on the surfaces of the fibers. These $\mathrm{Si} / \mathrm{C}$ fibers were found to show good capacitive retention when tested as LIB anode materials. ${ }^{64,71}$ Porous carbon fibers that contained Si nanoparticles were prepared through carbonization of composite fibers of PAN, PLLA and $\mathrm{Si}$, which exhibited large reversible capacity and relatively good cycling performance with a high current density of $200 \mathrm{mAh} / \mathrm{g} .{ }^{65}$ Recently, Hwang et al. ${ }^{81}$ reported an electrospinning process to produce core-shell fiber electrodes using a coaxial nozzle (Figure 7). Si nanoparticles in the core were wrapped by the carbon shell. Various issues of Si-based anode operations, such as pulverization, 
vulnerable contacts between $\mathrm{Si}$ and carbon conductor, and an unstable solid-electrolyte interface, were simultaneously addressed by the unique core-shell structure. Therefore the $\mathrm{Si} / \mathrm{C}$ core-shell fibers showed a gravimetric capacity as high as $1384 \mathrm{mAh} / \mathrm{g}$, a $5 \mathrm{~min}$ discharging rate capability with a capacity of $721 \mathrm{mAh} / \mathrm{g}$, and a cycle life of 300 cycles with almost no capacity loss.

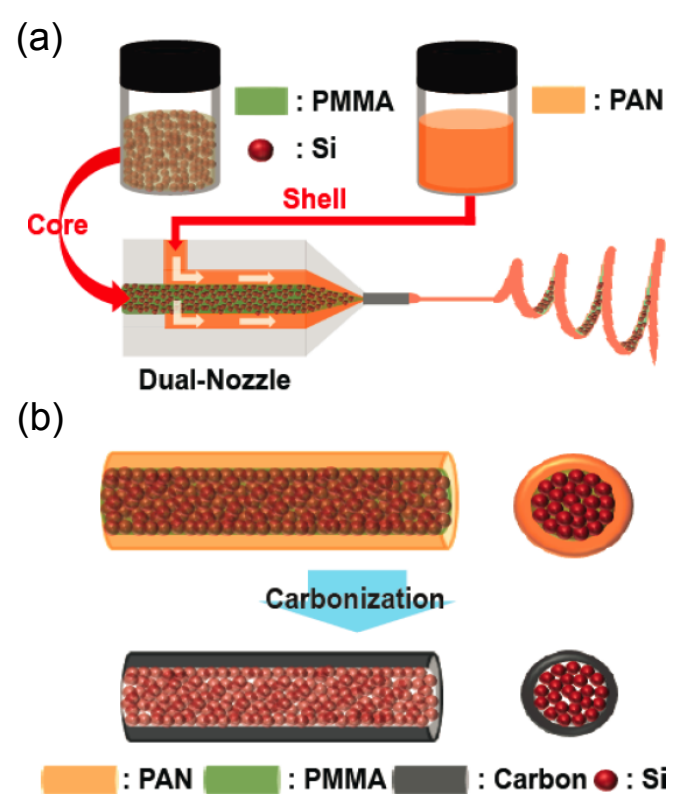

Figure 7. Schematic illustration of the electrospinning and carbonization steps to produce core-shell Si/C fibers. (a) The electrospinning process using a coaxial nozzle. The PMMA solution containing Si nanoparticles and the PAN solution were injected into the core and shell channels of the nozzle, respectively. (b) After electrospinning, stabilization, and carbonization steps were employed to complete the core-shell $1 D$ fibers consisting of Si nanoparticlse and carbon, respectively. Reprinted with permission from reference 81. Copyright 2012 American Chemical Society. Metallic tin (Sn) has also attracted tremendous interest as an anode material for LIBs due to its relatively high theoretical capacity of about $990 \mathrm{mAh} / \mathrm{g}$. Practical applications of Sn 
to LIBs is hampered by the poor cycling stability that results from the substantial volume changes that occur during charging and discharging. Electrospun carbon fibers with dispersed tin nanoparticles have been shown to improve the cycling stability of tin anodes considerably. "Sn@C” nanoparticles (comprising a Sn core wrapped by a thin, 10nm carbon layer) encapsulated in bamboo-like hollow carbon fibers were synthesized by carbonization of coaxially electrospun fibers. ${ }^{66}$ Specifically, as shown in Figure 8a, the Sn@C composite fibers were prepared by the electrospinning of PAN fibers containing tributyltin (TBT) dissolved into a mineral oil, followed by extraction of the mineral oil, most of which was located in the cores of the fibers, by $n$-octane, and finally by heating the fibers at $1000{ }^{\circ} \mathrm{C}$ in an $\mathrm{Ar} / \mathrm{H}_{2}$ atmosphere to carbonize the outer PAN shell and to decompose the TBT core to metallic $\mathrm{Sn}$. The $\mathrm{Sn} / \mathrm{C}$ composite electrode was compared to a commercial Sn nanopowder electrode in terms of the cycling performance (Figure 8b). The Sn/C composite electrode exhibited improved cycling performance and a high reversible specific capacity of over $800 \mathrm{mAh} / \mathrm{g}$ for the first 10 cycles, while maintaining a reversible capacity of about $737 \mathrm{mAh} / \mathrm{g}$ after 200 cycles. In contrast, the Sn nanopowder electrode had a discharge capacity that dropped rapidly after the first 40 cycles. Moreover, the $\mathrm{Sn} / \mathrm{C}$ composite electrode exhibited excellent rate performance (Figure 8c): it delivered a rate capacity of about $650 \mathrm{mAh} / \mathrm{g}$ when first cycled at $1 \mathrm{C}$ (where $1 \mathrm{C}$ rate represents a one-hour complete charge or discharge), ${ }^{84} 550 \mathrm{mAh} / \mathrm{g}$ at $3 \mathrm{C}, 480 \mathrm{mAh} / \mathrm{g}$ at $5 \mathrm{C}$, and finally back to $610 \mathrm{mAh} / \mathrm{g}$ at $1 \mathrm{C}$ again. Another type of $\mathrm{Sn} / \mathrm{C}$ composite electrode, porous multichannel carbon microtubes (SPMCTs) with Sn nanoparticles encapsulated, was prepared via the single-nozzle electrospinning of PMMA/PAN/tin octoate precursor solution and subsequent carbonization to remove PMMA and reduce tin 
oxide to tin nanoparticles (Figure 9) ${ }^{67}$ The SPMCT electrode also showed significantly improved cycling performance compared to the electrode made of Sn nanopowder alone. Electrospun carbon fibers with Sn nanoparticles incorporated were also synthesized using PVA as the precursor polymer. ${ }^{76,77}$

(a)
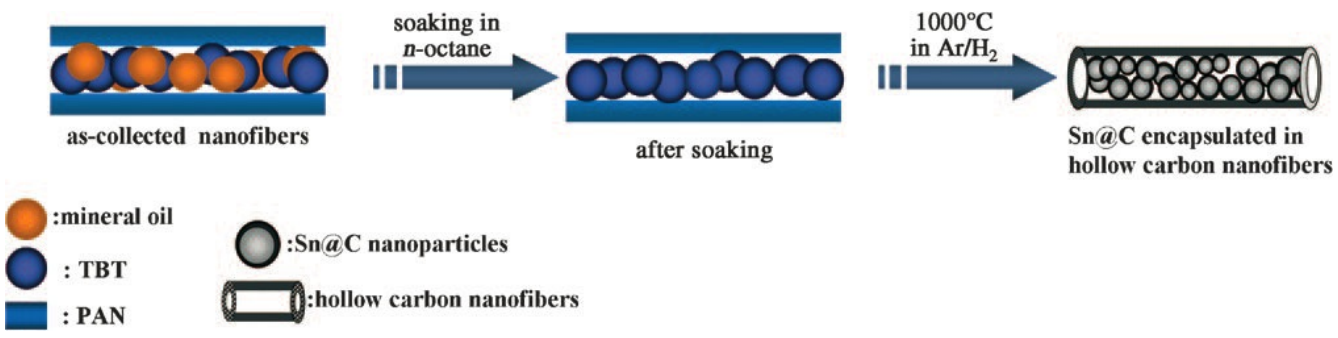

(b)

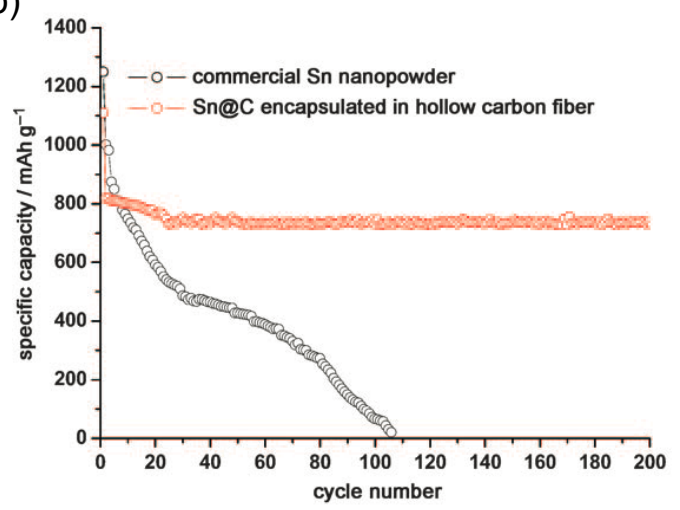

(c)

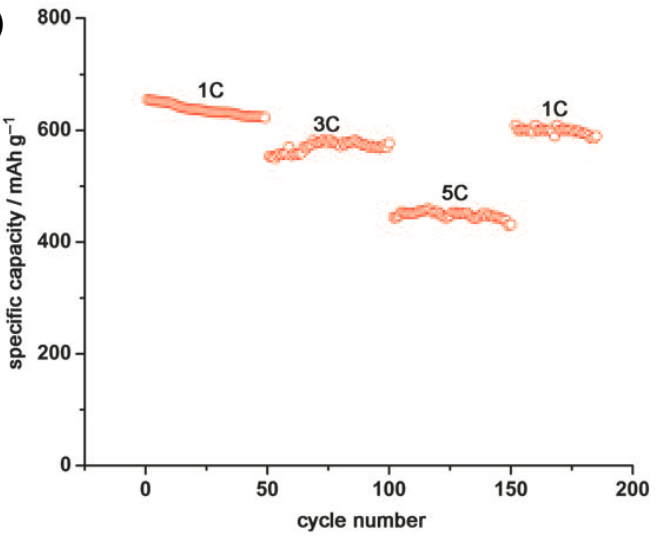

Figure 8. (a) Schematic illustration of preparation of Sn@carbon nanoparticles encapsulated in hollow carbon fibers. (b) Capacity - cycle number curves of a $\mathrm{Sn} / \mathrm{C}$ composite electrode and a commercial Sn nanopowder (diameter: $100 \mathrm{~nm}$ ) electrode at a cycling rate of $0.5 \mathrm{C}$. (c) Discharge capacity of a $\mathrm{Sn} / \mathrm{C}$ composite electrode as a function of discharge rate $(1-5 C)$. Reprinted with permission from reference 66. Copyright 2009 WILEY-VCH. 


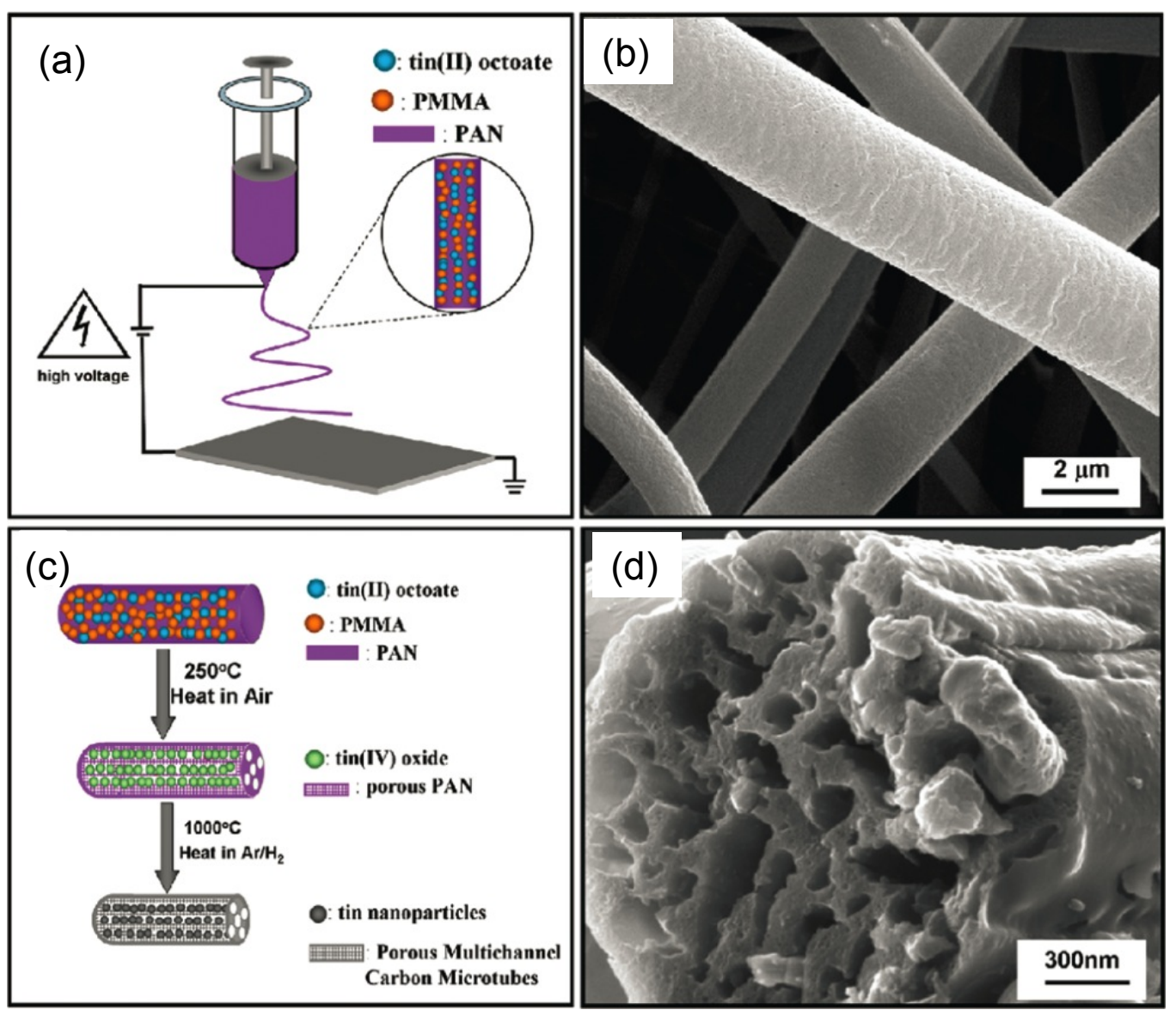

Figure 9. (a) Schematic illustration of co-electrospinning of a PMMA-PAN-tin octoate mixture in DMF using a single-needle nozzle. The inset (right) shows a magnified cartoon of the liquid filament. In the inset, the PMMA/DMF droplets are illustrated in orange, while the PAN/DMF liquid and tin octoate are illustrated in purple and darkblue, respectively. (b) Scanning electron microscopy (SEM) images of the as-collected core-shell fibers obtained via the single-nozzle electrospinning technique. (c) Proposed synthetic scheme for Sn nanoparticles encapsulated in porous multichannel carbon microtubes (SPMCTs). (d) High-magnification cross-sectional image of carbonized PMMA-PAN-tin octoate fibers that reveals the tubular structure of the SPMCTS. Reprinted with permission from reference 67. Copyright 2009 American Chemical Society. 
To improve LIB performance, other electrochemically active metallic particles such as $\mathrm{Co},{ }^{62} \mathrm{Fe},{ }^{63}, \mathrm{Mn},{ }^{6474} \mathrm{Ni}^{73}$, and $\mathrm{Cu}^{78}$ have also been incorporated into PAN-derived electrospun carbon fibers. Co/C composite fibers with diameters from 100 to $300 \mathrm{~nm}$ were found to exhibit a high reversible capacity of over $750 \mathrm{mAh} / \mathrm{g}$ and good rate capability of $678 \mathrm{mAh} / \mathrm{g}$ at $1 \mathrm{C}^{62}$ These improvements, compared to the LIB performance of pure carbon fibers, were ascribed to the incorporation of cobalt that led to an increase in the interfacial surface area between carbon and liquid electrolyte as well as an enhanced electronic conductivity. $\mathrm{Fe}_{3} \mathrm{O}_{4}$ has a higher lithium ion storage capacity $(924 \mathrm{mAh} / \mathrm{g})$ than does natural graphite. Electrospun $\mathrm{Fe}_{3} \mathrm{O}_{4} / \mathrm{C}$ fibers, annealed at a low temperature of $700{ }^{\circ} \mathrm{C}$ to generate disordered carbon and nanocrystalline $\mathrm{Fe}_{3} \mathrm{O}_{4}$, have been reported to show a very high capacity of $1007 \mathrm{mAh} / \mathrm{g}$ at the $80^{\text {th }}$ cycle and good rate

capability. ${ }^{63} \mathrm{Mn}$ or $\mathrm{Ni}$ or $\mathrm{Cu}$-loaded porous carbon fibers were prepared through electrospinning of PAN/Mn(OAc $)_{2}$ or $\mathrm{Ni}(\mathrm{OAc})_{2}$ or $\mathrm{Cu}(\mathrm{OAc})_{2}$ in $\mathrm{DMF}$ and were found to exhibit improved electronic conductivity and enhanced lithium storage. ${ }^{64,73,74,78}$

\section{Opportunities and challenges}

Electrospun carbon fibers have been synthesized by various techniques and enjoy the advantages of controllable fiber diameter, surface area, surface chemistry and degree of graphitization. Therefore these materials represent a promising platform technology for the development of energy storage devices, in particular for supercapacitors and lithium ion batteries. Conventional approaches for the preparation of carbon fibers include the substrate, spraying, vapor growth and plasmon-enhanced chemical vapor deposition methods. Compared to these techniques, electrospinning of precursor solutions 
followed by thermal treatment is a versatile and cost-effective fabrication method to produce 1-dimensional substrate-free mesostructured or nanostructured carbon-based materials, with the additional possibility to induce ordered internal morphologies such as core-shell, hollow or porous fibers, or multichannelled microtube configurations. The breadth of structural variability is a result of the considerable flexibility of this technique (1) to accommodate variations in composition of the precursor solutions, such as incorporation of carbon nanotubes, surfactants, catalysts, metal oxides, and multicomponent polymer mixtures, (2) to respond to differences in electrospinning parameters such as voltage, flow rate, single or dual nozzles, and collector types, and (3) to accommodate variations in thermal treatment conditions to modulate carbonization degree and therefore the microstructural parameters such as graphite crystal size, interlayer spacing, and the $\mathrm{sp}^{2} / \mathrm{sp}^{3}$ ratio. Moreover, the energy storage capabilities of electrospun carbon nanofiber-based electrodes are competitive with those of commercial supercapacitor and LIB devices. Caution should be exercised, however, when comparing the electrochemical performance of carbon nanofiber electrodes with those of commercial devices since many of the literature sources report the energy storage values relative to the mass of the active material, not to the total mass of the device. Commercial supercapacitors can attain a capacitance of $\sim 4000 \mathrm{~F}$ with a cell mass of $\sim 0.5 \mathrm{~kg}$ (i.e., $\sim 8$ F/g cell), ${ }^{85}$ Generally the weight of the active material accounts for approximately $10 \%$ of the total cell mass for supercapacitor devices, and thus the gravimetric capacitance of commercial supercapacitors with respect to the mass of the active material is $\sim 100 \mathrm{~F} / \mathrm{g}$. Commercial LIBs usually exhibit a reversible capacity of $1000 \mathrm{mAh}$ with a battery mass of $\sim 0.5 \mathrm{~kg},{ }^{86}$ giving a gravimetric capacity of $10 \mathrm{mAh} / \mathrm{g}$ with respective to the mass of the 
anode material. As shown in Tables 1 and 2, the supercapacitor capacitances $(\mathrm{F} / \mathrm{g})$ and LIB capacity $(\mathrm{mAh} / \mathrm{g})$ of various electrospun carbon fiber-based electrode materials already exceed the corresponding values for commercial devices. In addition to carbon nanofibers, other forms of nanocarbons, in particular carbon nanotubes and graphenes, have also been investigated extensively as next-generation energy storage materials. In CNT or graphene-based energy storage devices, substrates or binders are usually required, which may reduce the energy densities and power densities of such devices due to the necessary incorporation of additional inactive materials. However, CNTs and graphene have remarkably higher surface areas and electrical conductivities than do electrospun carbon fibers. These properties provide for enhanced energy storage capacity as well as an excellent rate capability, due to simultaneously facilitated electron transport, ion diffusion and redox reaction rates. Therefore, development of electrospun carbon fibers with improved conductivity and high surface area, as well as controlled pore size/distribution and new chemical functionalities is essential to meet the current challenges for energy-related applications such as improving power density for supercapacitor devices as well as increasing lithium ion storage capacity and rate performance for LIB applications.

High conductivity is of great significance for the development of both supercapacitor devices and LIBs. However, conductivities of electrospun carbon nanofibers are usually significantly lower than those of graphenes and carbon nanotubes because the carbon precursor used in electrospinning, PAN in most cases, cannot achieve a high degree of graphitization during carbonization. PAN-derived electrospun carbon nanofibers are not completely graphitized even when carbonized at a very high 
temperature of $2800{ }^{\circ} \mathrm{C}$, as evidenced by an interlayer spacing of $0.341 \mathrm{~nm}$ and a low electrical conductivity of $20 \mathrm{~S} / \mathrm{cm} .{ }^{61}$ In order to improve conductivities, carbon nanotubes and metallic nanoparticles have been incorporated into PAN-based carbon fibers. A high content of metal nanoparticles or CNTs leads to poor electrospinnability of the precursor solution, however, and only minor improvements in conductivity have been achieved through the addition of conductive components into the precursor mixtures. For example, incorporation of $0.8 \mathrm{wt} \%$ MWCNTs gave rise to a small increase in electrical conductivity from 0.86 to $5.32 \mathrm{~S} / \mathrm{cm}$ for electrospun carbon fiber webs treated at $700{ }^{\circ} \mathrm{C}^{54}$, Chemical modification of electrospun carbon fibers after thermal treatment to improve conductivities and electrochemical capacitances for supercapacitor applications, on the other hand, has not received as much attention. Opportunities exist to exploit postcarbonization chemical modification techniques to create composite materials with increased conductivities and/or novel functionalities (e.g., pseudocapacitance), since these techniques are not limited by the electrospinnability of the precursor solutions. A wide range of new chemistries and even micro- or nano-textures could be incorporated into the electrospun carbon nanofiber webs through the use of surface modification techniques such as click chemistry, electrodeposition or electropolymerization of redoxactive species, or layer-by-layer deposition of conductive components (i.e., carbon nanotubes with positive and negative surface charges).

Specific surface areas of porous carbon materials are closely related to their electrochemical performance in both supercapacitor devices and lithium ion batteries. High surface areas, which accelerate ion transport, can accommodate large quantities of ions as well as improve rate capability. As mentioned earlier, with catalysts such as $\mathrm{ZnCl}_{2}$, 
a decrease in carbon fiber diameters with a corresponding increase in surface area has been achieved. ${ }^{51}$ The addition of cellulose acetate into PAN/DMF solutions resulted in an increase in surface area from 740 to $1160 \mathrm{~m}^{2} / \mathrm{g}$ and therefore improved capacitance from 141 to $245 \mathrm{~F} / \mathrm{g}$ at a current density of $1 \mathrm{~mA} / \mathrm{cm}^{2} .^{53}$ The composition of the precursor solutions as well as the nature of the carbon precursor itself could have significant effects on the carbonization process. Another possible opportunity lies in utilizing different catalysts to modulate the thermal treatment process, and to study the effects of catalysts on surface area of the resulting carbon nanofiber webs. Highly porous fibers with enhanced surface areas might be created using novel templating methods such as use of a PAN-b-PMMA block copolymer, with the capability to burn off the MMA component during carbonization, therefore creating unusual types of pores inside of the fibers.

Another interesting aspect of nanocarbon-based energy materials is control of ion adsorption ability and $\mathrm{Li}^{+}$storage capacity through manipulation of pore structures on the carbon surface. Different types of pores can be generated in the electrospun carbon nanofiber webs: large inter-fiber spaces, macropores ( $>50 \mathrm{~nm}$ in average diameters), mesopores $(2-50 \mathrm{~nm}$ in average diameters), and micropores $(<2 \mathrm{~nm}$ in average diameters). The size and structure of large inter-fiber spaces determine the porosity and bulk density of the electrospun webs, which is important for the volumetric storage capacity. In addition, the characteristic length scale of ion diffusion pathways is related to the dimension of these large inter-fiber spaces. Therefore optimization of web density and inter-fiber distance could lead to improved rate capability. However, the sizes of these large inter-fiber spaces tend to correlate with fiber diameter, so that these two properties are difficult to control independently. Hot-press treatment during stabilization 
and in situ control of pressure applied to the precursor polymer web during carbonization can be used to modulate the size of large inter-fiber spaces in the resultant carbon fiber webs.

It has been shown that the formation of micropores on the fiber surface could lead to good rate performance. ${ }^{47,49}$ To control the extent of micropore formation in individual fibers, conventional activation steps (e.g, using steam, base and acid as the activation agents) have been utilized, since the micropores are formed during the evolution of different gaseous species such as $\mathrm{CO}, \mathrm{CO}_{2}$ and various types of hydrocarbons, which depends strongly upon the thermal treatment conditions. Mesopores and macropores are often introduced to carbon fibers in order to enhance surface area, in most cases through the use of an additional carbon precursor that acts as a pore-former or through the inclusion of some templates or sacrificial materials in the electrospinning solution. In addition, hierarchical pore structure can be introduced to electrospun fiber webs through the use of electrospinning solutions composed of polymer $\mathrm{A} /$ polymer $\mathrm{B} /$ solvent/nonsolvent. ${ }^{87}$ The mesopores formed inside the fibers themselves are generated as the solution phase-separates into polymer-rich and solvent-rich domains during the electrospinning process.

Another aspect of electrospun carbon fiber-based energy materials that has seen less attention to date is the mechanical properties of the free-standing webs, which generally need to be enhanced because carbon fibers are often brittle and must be handled with caution. This is of practical importance if flexible, printable and wearable carbon nanofiber-based energy storage devices are to be integrated into smart clothing, sensors, wearable electronics and gene/drug delivery systems. In addition, theoretical guidance is 
scarce for the design of electrospun carbon nanofibers, in particular when combined with other materials to give new functionalities. Mathematical modeling and simulation tools developed for porous electrode thermodynamics and kinetics could be adapted to describe the electrochemical properties of electrospun carbon nanofiber webs.

Several challenges still remain to be overcome before industrial scale usage of this technique is realized. There are limitations on the types of materials that can be fabricated by electrospinning, and it is sometimes difficult to formulate solutions with the desired chemical properties that are at the same time spinnable into uniform fibers of the desired size and morphology. The carbonization processes involve complex physical and chemical changes, and the effects of the precursor and the solution composition on the development of graphiteic structures are not fully understood. To optimize energy storage capability, precise control of fiber diameters, porosity, and distribution of active components in the fibers is of immediate importance. Controlled synthesis and modification techniques for carbon nanofibers with enhanced specificity and high flexibility might be necessary to improve electrochemical performance. Additional challenges are associated with scale-up of the electrospinning technique and down-stream processing, which are essential for the use of electrospun carbon fibers in large scale manufacturing of energy storage devices. Multi-jet nozzles or free surface electrospinning ${ }^{34}$ are possible strategies to increase productivity and achieve large scale nanofiber production.

\section{Conclusion}


Among various fabrication methods for ultrafine carbon fibers, the technique of electrospinning followed by thermal treatment is undergoing intense scrutiny for energyrelated applications. This technique provides relatively flexible control over morphology, degree of graphitization, and chemical functionality of the resulting 1D nanostructured carbon fibers. Therefore optimization of the electrochemical properties of electrospun carbon fibers for the development of advanced energy storage devices is an area ripe for development. Tables 1 and 2 summarize the recent advances in using electrospun carbon fibers as electrode materials for supercapacitors and lithim-ion batteries. We have discussed briefly the principles of the electrospinning/thermal treatment method as well as the characterization techniques for the resultant carbon fibers. For the applications of electrospun carbon fibers to supercapacitor devices, increasing conductivity and surface area are the most frequently adopted strategies to improve the electrocapactive performance. In LIB applications, most published accounts report electrospun carbon fibers serving as supports or structural buffers for $\mathrm{Si}$ or $\mathrm{Sn}$, which have much higher theoretical values for lithium ion storage than does graphite. These composite fibers have been in the forms of either core ( $\mathrm{Si} / \mathrm{Sn})$-shell (carbon) fibers, or $\mathrm{Si} / \mathrm{Sn}$ nanoparticles deposited on the carbon fiber surfaces. Future generations of supercapacitors are expected to come close to current lithium-ion batteries in terms of high energy density maintained at high power density. This may be achieved by discovering new materials that combine double layer capacitance and pseudocapacitance, and by developing hybrid systems. On the other hand, the cycling performance of lithium ion batteries is expected to improve significantly, to a level approaching the cycling stability of supercapacitors, with the objective of retaining the initial capacity even after more than 1000 charge/discharge 
cycles. Good progress toward this goal has been made, but further optimization by developing structural buffers with well-defined nano-scale geometries is waranted.

\section{Acknowledgements}

The authors would like to thank U.S. Department of Energy for financial support during the course of this work. 


\section{References}

(1) Bruce, P. G.; Scrosati, B.; Tarascon, J. M.: Nanomaterials for rechargeable lithium batteries. Angew Chem Int Edit 2008, 47, 2930-2946.

(2) Cabana, J.; Monconduit, L.; Larcher, D.; Palacin, M. R.: Beyond Intercalation-Based Li-Ion Batteries: The State of the Art and Challenges of Electrode Materials Reacting Through Conversion Reactions. Adv Mater 2010, 22, E170-E192.

(3) Tarascon, J. M.; Recham, N.; Armand, M.; Chotard, J. N.; Barpanda, P.; Walker, W.; Dupont, L.: Hunting for Better Li-Based Electrode Materials via Low Temperature Inorganic Synthesis. Chem Mater 2010, 22, 724-739.

(4) Hall, P. J.; Mirzaeian, M.; Fletcher, S. I.; Sillars, F. B.; Rennie, A. J. R.; Shitta-Bey, G. O.; Wilson, G.; Cruden, A.; Carter, R.: Energy storage in electrochemical capacitors: designing functional materials to improve performance. Energ Environ Sci 2010, 3, 1238-1251.

(5) Xu, C. J.; Kang, F. Y.; Li, B. H.; Du, H. D.: Recent progress on manganese dioxide based supercapacitors. J Mater Res 2010, 25, 1421-1432.

(6) Zhang, L. L.; Zhao, X. S.: Carbon-based materials as supercapacitor electrodes. Chem Soc Rev 2009, 38, 2520-2531.

(7) Simon, P.; Gogotsi, Y.: Materials for electrochemical capacitors. Nat Mater 2008, 7, 845-854.

(8) Zhai, Y. P.; Dou, Y. Q.; Zhao, D. Y.; Fulvio, P. F.; Mayes, R. T.; Dai, S.: Carbon Materials for Chemical Capacitive Energy Storage. Adv Mater 2011, 23, 48284850. 
(9) Winter, M.; Brodd, R. J.: What are batteries, fuel cells, and supercapacitors? Chem Rev 2004, 104, 4245-4269.

(10) Bae, J.; Song, M. K.; Park, Y. J.; Kim, J. M.; Liu, M. L.; Wang, Z. L.: Fiber Supercapacitors Made of Nanowire-Fiber Hybrid Structures for Wearable/Flexible Energy Storage. Angew Chem Int Edit 2011, 50, 1683-1687.

(11) Stoller, M. D.; Ruoff, R. S.: Best practice methods for determining an electrode material's performance for ultracapacitors. Energ Environ Sci 2010, 3, 12941301.

(12) Pandolfo, A. G.; Hollenkamp, A. F.: Carbon properties and their role in supercapacitors. J Power Sources 2006, 157, 11-27.

(13) Miller, J. R.; Simon, P.: Materials science - Electrochemical capacitors for energy management. Science 2008, 321, 651-652.

(14) Futaba, D. N.; Hata, K.; Yamada, T.; Hiraoka, T.; Hayamizu, Y.; Kakudate, Y.; Tanaike, O.; Hatori, H.; Yumura, M.; Iijima, S.: Shape-engineerable and highly densely packed single-walled carbon nanotubes and their application as supercapacitor electrodes. Nat Mater 2006, 5, 987-994.

(15) Zhu, Y. W.; Murali, S.; Stoller, M. D.; Ganesh, K. J.; Cai, W. W.; Ferreira, P. J.; Pirkle, A.; Wallace, R. M.; Cychosz, K. A.; Thommes, M.; Su, D.; Stach, E. A.; Ruoff, R. S.: Carbon-Based Supercapacitors Produced by Activation of Graphene. Science 2011, 332, 1537-1541.

(16) Xie, K.; Qin, X. T.; Wang, X. Z.; Wang, Y. N.; Tao, H. S.; Wu, Q.; Yang, L. J.; Hu, Z.: Carbon Nanocages as Supercapacitor Electrode Materials. Adv Mater 2012, $24,347-+$. 
(17) Lei, Z. B.; Christov, N.; Zhang, L. L.; Zhao, X. S.: Mesoporous carbon nanospheres with an excellent electrocapacitive performance. Journal of Materials Chemistry 2011, 21, 2274-2281.

(18) Wu, N. L.: Nanocrystalline oxide supercapacitors. Mater Chem Phys 2002, $75,6-11$.

(19) Brousse, T.; Toupin, M.; Dugas, R.; Athouel, L.; Crosnier, O.; Belanger, D.: Crystalline $\mathrm{MnO} 2$ as possible alternatives to amorphous compounds in electrochemical supercapacitors. $J$ Electrochem Soc 2006, 153, A2171-A2180.

(20) Tarascon, J. M.; Armand, M.: Issues and challenges facing rechargeable lithium batteries. Nature 2001, 414, 359-367.

(21) Kaskhedikar, N. A.; Maier, J.: Lithium Storage ion Carbon Nanostructures. Adv Mater 2009, 21, 2664-2680.

(22) Song, T.; Xia, J. L.; Lee, J. H.; Lee, D. H.; Kwon, M. S.; Choi, J. M.; Wu, J.; Doo, S. K.; Chang, H.; Il Park, W.; Zang, D. S.; Kim, H.; Huang, Y. G.; Hwang, K. C.; Rogers, J. A.; Paik, U.: Arrays of Sealed Silicon Nanotubes As Anodes for Lithium Ion Batteries. Nano Lett 2010, 10, 1710-1716.

(23) Chan, C. K.; Peng, H. L.; Liu, G.; McIlwrath, K.; Zhang, X. F.; Huggins, R. A.; Cui, Y.: High-performance lithium battery anodes using silicon nanowires. Nat Nanotechnol 2008, 3, 31-35.

(24) Yu, Y.; Gu, L.; Zhu, C. B.; Tsukimoto, S.; van Aken, P. A.; Maier, J.: Reversible Storage of Lithium in Silver-Coated Three-Dimensional Macroporous Silicon. Adv Mater 2010, 22, 2247-+. 
(25) Deng, D.; Kim, M. G.; Lee, J. Y.; Cho, J.: Green energy storage materials: Nanostructured TiO2 and Sn-based anodes for lithium-ion batteries. Energ Environ Sci 2009, 2, 818-837.

(26) Amatucci, G.; Tarascon, J. M.: Optimization of insertion compounds such as LiMn2O4 for Li-ion batteries. $J$ Electrochem Soc 2002, 149, K31-K46.

(27) Li, N. C.; Patrissi, C. J.; Che, G. L.; Martin, C. R.: Rate capabilities of nanostructured LiMn2O4 electrodes in aqueous electrolyte. J Electrochem Soc 2000, 147, 2044-2049.

(28) Whittingham, M. S.: Lithium batteries and cathode materials. Chem Rev 2004, 104, 4271-4301.

(29) Kang, B.; Ceder, G.: Battery materials for ultrafast charging and discharging. Nature 2009, 458, 190-193.

(30) Padhi, A. K.; Nanjundaswamy, K. S.; Goodenough, J. B.: Phosphoolivines as positive-electrode materials for rechargeable lithium batteries. $J$ Electrochem Soc 1997, 144, 1188-1194.

(31) Wang, Y.; Cao, G. Z.: Developments in nanostructured cathode materials for high-performance lithium-ion batteries. Adv Mater 2008, 20, 2251-2269.

(32) Li, D.; Xia, Y. N.: Electrospinning of nanofibers: Reinventing the wheel? Adv Mater 2004, 16, 1151-1170.

(33) Rutledge, G. C.; Fridrikh, S. V.: Formation of fibers by electrospinning. Adv Drug Deliver Rev 2007, 59, 1384-1391.

(34) Forward, K. M.; Rutledge, G. C.: Free surface electrospinning from a wire electrode. Chem Eng J 2012, 183, 492-503. 
(35) Im, J. S.; Woo, S. W.; Jung, M. J.; Lee, Y. S.: Improved capacitance characteristics of electrospun ACFs by pore size control and vanadium catalyst. $J$ Colloid Interface Sci 2008, 327, 115-119.

(36) Pimenta, M. A.; Dresselhaus, G.; Dresselhaus, M. S.; Cancado, L. G.; Jorio, A.; Saito, R.: Studying disorder in graphite-based systems by Raman spectroscopy. Phys Chem Chem Phys 2007, 9, 1276-1291.

(37) Cuomo, J. J.; Doyle, J. P.; Bruley, J.; Liu, J. C.: Sputter Deposition of Dense Diamond-Like Carbon-Films at Low-Temperature. Appl Phys Lett 1991, 58, 466468.

(38) Li, L. H.; Zhang, H. Q.; Zhang, Y. H.; Chu, P. K.; Tian, X. B.; Xia, L. F.; Ma, X. X.: Structural analysis of arc deposited diamond-like carbon films by Raman and X-ray photoelectron spectroscopy. Mat Sci Eng B-Solid 2002, 94, 95-101.

(39) Paik, N.: Raman and XPS studies of DLC films prepared by a magnetron sputter-type negative ion source. Surf Coat Tech 2005, 200, 2170-2174.

(40) Iwashita, N.; Park, C. R.; Fujimoto, H.; Shiraishi, M.; Inagaki, M.: Specification for a standard procedure of X-ray diffraction measurements on carbon materials. Carbon 2004, 42, 701-714.

(41) Zhang, Y. X.; Rutledge, G. C.: Electrical Conductivity of Electrospun Polyaniline and Polyaniline-Blend Fibers and Mats. Macromolecules 2012, 45, 42384246.

(42) McCreery, R. L.: Advanced carbon electrode materials for molecular electrochemistry. Chem Rev 2008, 108, 2646-2687. 
(43) Cline, K. K.; Mcdermott, M. T.; Mccreery, R. L.: Anomalously SlowElectron Transfer at Ordered Graphite-Electrodes - Influence of Electronic Factors and Reactive Sites. J Phys Chem-Us 1994, 98, 5314-5319.

(44) Kim, C.; Yang, K. S.: Electrochemical properties of carbon nanofiber web as an electrode for supercapacitor prepared by electrospinning. Appl Phys Lett 2003, 83, 1216-1218.

(45) Kim, C.; Park, S. H.; Lee, W. J.; Yang, K. S.: Characteristics of supercapaitor electrodes of PBI-based carbon nanofiber web prepared by electrospinning. Electrochim Acta 2004, 50, 877-881.

(46) Kim, C.; Kim, J. S.; Kim, S. J.; Lee, W. J.; Yang, K. S.: Supercapacitors prepared from carbon nanofibers electrospun from polybenzimidazol. J Electrochem Soc 2004, 151, A769-A773.

(47) Kim, C.; Yang, K. S.; Lee, W. J.: The use of carbon nanofiber electrodes prepared by electrospinning for electrochemical supercapacitors. Electrochem Solid St 2004, 7, A397-A399.

(48) Kim, C.; Choi, Y. O.; Lee, W. J.; Yang, K. S.: Supercapacitor performances of activated carbon fiber webs prepared by electrospinning of PMDA-ODA poly(amic acid) solutions. Electrochim Acta 2004, 50, 883-887.

(49) Kim, C.: Electrochemical characterization of electrospun activated carbon nanofibres as an electrode in supercapacitors. J Power Sources 2005, 142, 382-388.

$$
\text { Ju, Y. W.; Choi, G. R.; Jung, H. R.; Kim, C.; Yang, K. S.; Lee, W. J.: A }
$$

hydrous ruthenium oxide-carbon nanofibers composite electrodes prepared by electrospinning. J Electrochem Soc 2007, 154, A192-A197. 
(51) Kim, C.; Ngoc, B. T. N.; Yang, K. S.; Kojima, M.; Kim, Y. A.; Kim, Y. J.; Endo, M.; Yang, S. C.: Self-sustained thin webs consisting of porous carbon nanofibers for supercapacitors via the electrospinning of polyacrylonitrile solutions containing zinc chloride. Adv Mater 2007, 19, 2341-+.

(52) Ju, Y. W.; Choi, G. R.; Jung, H. R.; Lee, W. J.: Electrochemical properties of electrospun PAN/MWCNT carbon nanofibers electrodes coated with polypyrrole. Electrochim Acta 2008, 53, 5796-5803.

(53) Ju, Y. W.; Park, S. H.; Jung, H. R.; Lee, W. J.: Electrospun Activated Carbon Nanofibers Electrodes Based on Polymer Blends. J Electrochem Soc 2009, 156, A489-A494.

(54) Guo, Q. H.; Zhou, X. P.; Li, X. Y.; Chen, S. L.; Seema, A.; Greiner, A.; Hou, H. Q.: Supercapacitors based on hybrid carbon nanofibers containing multiwalled carbon nanotubes. Journal of Materials Chemistry 2009, 19, 2810-2816.

(55) Li, J.; Liu, E. H.; Li, W.; Meng, X. Y.; Tan, S. T.: Nickel/carbon nanofibers composite electrodes as supercapacitors prepared by electrospinning. $J$ Alloy Compd 2009, 478, 371-374.

(56) Niu, H. T.; Zhang, J.; Xie, Z. L.; Wang, X. G.; Lin, T.: Preparation, structure and supercapacitance of bonded carbon nanofiber electrode materials. Carbon 2011, 49, 2380-2388.

(57) Kim, B. H.; Yang, K. S.; Woo, H. G.: Thin, bendable electrodes consisting of porous carbon nanofibers via the electrospinning of polyacrylonitrile containing tetraethoxy orthosilicate for supercapacitor. Electrochem Commun 2011, 13, 1042-1046. 
(58) Kim, B. H.; Yang, K. S.; Woo, H. G.: Preparation and Electrochemical Properties of Carbon Nanofiber Composite Dispersed with Silver Nanoparticles Using Polyacrylonitrile and beta-Cyclodextrin. J Nanosci Nanotechno 2011, 11, 7193-7197.

(59) Kim, B. H.; Yang, K. S.; Kim, Y. A.; Kim, Y. J.; An, B.; Oshida, K.:

Solvent-induced porosity control of carbon nanofiber webs for supercapacitor. J Power Sources 2011, 196, 10496-10501.

(60) Park, S. J.; Im, S. H.: Electrochemical behaviors of PAN/Ag-based carbon nanofibers by electrospinning. B Korean Chem Soc 2008, 29, 777-781.

(61) Kim, C.; Yang, K. S.; Kojima, M.; Yoshida, K.; Kim, Y. J.; Kim, Y. A.; Endo, M.: Fabrication of electrospinning-derived carbon nanofiber webs for the anode material of lithium-ion secondary batteries. Adv Funct Mater 2006, 16, 2393-2397.

(62) Wang, L.; Yu, Y.; Chen, P. C.; Chen, C. H.: Electrospun carbon-cobalt composite nanofiber as an anode material for lithium ion batteries. Scripta Mater 2008, $58,405-408$.

(63) Wang, L.; Yu, Y.; Chen, P. C.; Zhang, D. W.; Chen, C. H.: Electrospinning synthesis of $\mathrm{C} / \mathrm{Fe} 3 \mathrm{O} 4$ composite nanofibers and their application for high performance lithium-ion batteries. J Power Sources 2008, 183, 717-723.

(64) Ji, L. W.; Medford, A. J.; Zhang, X. W.: Porous carbon nanofibers loaded with manganese oxide particles: Formation mechanism and electrochemical performance as energy-storage materials. Journal of Materials Chemistry 2009, 19, 5593-5601.

(65) Ji, L. W.; Zhang, X. W.: Fabrication of porous carbon/Si composite nanofibers as high-capacity battery electrodes. Electrochem Commun 2009, 11, 11461149. 
(66) Yu, Y.; Gu, L.; Wang, C. L.; Dhanabalan, A.; van Aken, P. A.; Maier, J.: Encapsulation of Sn@carbon Nanoparticles in Bamboo-like Hollow Carbon Nanofibers as an Anode Material in Lithium-Based Batteries. Angew Chem Int Edit 2009, 48, 64856489.

(67) Yu, Y.; Gu, L.; Zhu, C. B.; van Aken, P. A.; Maier, J.: Tin Nanoparticles Encapsulated in Porous Multichannel Carbon Microtubes: Preparation by Single-Nozzle Electrospinning and Application as Anode Material for High-Performance Li-Based Batteries. J Am Chem Soc 2009, 131, 15984-+.

(68) Ji, L. W.; Zhang, X. W.: Generation of activated carbon nanofibers from electrospun polyacrylonitrile-zinc chloride composites for use as anodes in lithium-ion batteries. Electrochem Commun 2009, 11, 684-687.

(69) Ji, L. W.; Jung, K. H.; Medford, A. J.; Zhang, X. W.: Electrospun polyacrylonitrile fibers with dispersed Si nanoparticles and their electrochemical behaviors after carbonization. Journal of Materials Chemistry 2009, 19, 4992-4997.

(70) Fan, X.; Zou, L.; Zheng, Y. P.; Kang, F. Y.; Shen, W. C.: Electrospinning Preparation of Nanosilicon/Disordered Carbon Composite as Anode Materials in Li-Ion Battery. Electrochem Solid St 2009, 12, A199-A201.

(71) Ji, L. W.; Zhang, X. W.: Electrospun carbon nanofibers containing silicon particles as an energy-storage medium. Carbon 2009, 47, 3219-3226.

(72) Ji, L. W.; Lin, Z.; Medford, A. J.; Zhang, X. W.: Porous carbon nanofibers from electrospun polyacrylonitrile/SiO2 composites as an energy storage material. Carbon 2009, 47, 3346-3354. 
(73) Ji, L. W.; Lin, Z.; Medford, A. J.; Zhang, X. W.: In-Situ Encapsulation of Nickel Particles in Electrospun Carbon Nanofibers and the Resultant Electrochemical Performance. Chem-Eur J 2009, 15, 10718-10722.

(74) Ji, L. W.; Zhang, X. W.: Manganese oxide nanoparticle-loaded porous carbon nanofibers as anode materials for high-performance lithium-ion batteries. Electrochem Commun 2009, 11, 795-798.

(75) Ji, L. W.; Zhang, X. W.: Fabrication of porous carbon nanofibers and their application as anode materials for rechargeable lithium-ion batteries. Nanotechnology 2009, 20.

(76) Zou, L.; Gan, L.; Kang, F. Y.; Wang, M. X.; Shen, W. C.; Huang, Z. H.: $\mathrm{Sn} / \mathrm{C}$ non-woven film prepared by electrospinning as anode materials for lithium ion batteries. J Power Sources 2010, 195, 1216-1220.

(77) Zou, L.; Gan, L.; Lv, R. T.; Wang, M. X.; Huang, Z. H.; Kang, F. Y.; Shen, W. C.: A film of porous carbon nanofibers that contain $\mathrm{Sn} / \mathrm{SnOx}$ nanoparticles in the pores and its electrochemical performance as an anode material for lithium ion batteries. Carbon 2011, 49, 89-95.

(78) Ji, L. W.; Lin, Z.; Zhou, R.; Shi, Q.; Toprakci, O.; Medford, A. J.; Millns, C. R.; Zhang, X. W.: Formation and electrochemical performance of copper/carbon composite nanofibers. Electrochim Acta 2010, 55, 1605-1611.

(79) Choi, H. S.; Lee, J. G.; Lee, H. Y.; Kim, S. W.; Park, C. R.: Effects of surrounding confinements of Si nanoparticles on Si-based anode performance for lithium ion batteries. Electrochim Acta 2010, 56, 790-796. 
(80) Toprakci, O.; Ji, L. W.; Lin, Z.; Toprakci, H. A. K.; Zhang, X. W.: Fabrication and electrochemical characteristics of electrospun LiFePO4/carbon composite fibers for lithium-ion batteries. J Power Sources 2011, 196, 7692-7699.

(81) Hwang, T. H.; Lee, Y. M.; Kong, B. S.; Seo, J. S.; Choi, J. W.:

Electrospun Core-Shell Fibers for Robust Silicon Nanoparticle-Based Lithium Ion Battery Anodes. Nano Lett 2012, 12, 802-807.

(82) Kim, H.; Han, B.; Choo, J.; Cho, J.: Three-Dimensional Porous Silicon Particles for Use in High-Performance Lithium Secondary Batteries. Angew Chem Int Edit 2008, 47, 10151-10154.

(83) Zhang, X. W.; Patil, P. K.; Wang, C. S.; Appleby, A. J.; Little, F. E.; Cocke, D. L.: Electrochemical performance of lithium ion battery, nano-silicon-based, disordered carbon composite anodes with different microstructures. J Power Sources 2004, 125, 206-213.

(84) Zhang, H. G.; Yu, X. D.; Braun, P. V.: Three-dimensional bicontinuous ultrafast-charge and -discharge bulk battery electrodes. Nat Nanotechnol 2011, 6, 277 281.

(85) Chu, A.; Braatz, P.: Comparison of commercial supercapacitors and highpower lithium-ion batteries for power-assist applications in hybrid electric vehicles I. Initial characterization. J Power Sources 2002, 112, 236-246.

(86) Li, J.; Murphy, E.; Winnick, J.; Kohl, P. A.: Studies on the cycle life of commercial lithium ion batteries during rapid charge-discharge cycling. J Power Sources 2001, 102, 294-301. 
(87) Yang, Y.; Centrone, A.; Chen, L.; Simeon, F.; Hatton, T. A.; Rutledge, G. C.: Highly porous electrospun polyvinylidene fluoride (PVDF)-based carbon fiber. Carbon 2011, 49, 3395-3403. 